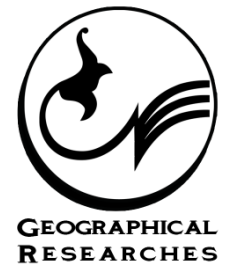

\title{
Investigation of Urban Sprawl Using Spatial Planning Models in Mashhad
}

\section{ART I C L E I N F O}

\section{Article Type}

Original Research

\section{Authors}

Rabbani Abolfazli Gh. * $M A$

Shafaghi S. ${ }^{1} \mathrm{PhD}$

Rahnama M.R. ${ }^{2} P h D$
How to cite this article Rabbani Abolfazli G, Shafaghi S Rahnama M. R. Investigation of urban sprawl using spatial planning models in Mashhad. Geographical Researches Quarterly Journal. 2018;33(2): 90-107.
*Department of Geography and Urban Planning, Research Institute of Shakhes Pajouh, Isfahan, Iran. ${ }^{1}$ Department of Geography and Urban Planning, Research Institute of Shakhes Pajouh, Isfahan, Iran. ${ }^{2}$ Department of Geography, Faculty of Letters and Humani-ties, Ferdowsi University of Mashhad, Mashhad, Iran

\section{*Correspondence}

Address: Department of Geography and Urban Planning, Research Institute of Shakhes Pajouh, Isfahan, Iran. Phone: -

Fax: -

ghazaleh.rabbani@gmail.com

\section{Article History}

Received: December 27, 2017

Accepted: August 13, 2018

ePublished: September 17, 2018

\begin{abstract}
A B S T R A C T
Introduction and Background Urban sprawl is a key subject of interest among urban planners and policy-makers, which needs to measure and monitor in order to overcome its impacts. In fact, urban expansion, and sprawl modeling is an interdisciplinary field as it involves numerous scientific areas such as geographical information system (GIS), complexity theory, urban geography, and remote sensing. Aims The present study aims to generate an urban sprawl model using spatial planning approaches in Mashhad city. This type of measurement of physical growth in urban districts of Mashhad city is essential to urban planners and decision-makers who immediately need updated database for planning and management purposes.

Methodology For this purpose, modified relative Shannon's entropy together with hierarchical clustering analysis was considered. Five geo-statistical variables were considered as independent input variables to measure sprawl model. Thus, to reveal probability relations between sprawl indices and aforementioned independent variables the correlation coefficients were used.

Conclusion The results revealed an analogous output for both relative entropy measurement and hierarchical clustering analysis through the sprawl model. On this basis, three municipality districts were categorized as prone zones of the study area in regard of sprawl expansion pattern. A direct and significant correlation between sprawl indices and informal settlements was estimated equal to 0.44 through municipality districts. Also, direct correlations ( $\mathrm{R}=0.32$ to 0.30 ) were observed between sprawl index and frequency of crimes and building parcel size. Contrarily, the result revealed a reverse correlation $(\mathrm{R}=-0.50)$ between sprawl index and land price index was explored based on each districts. It seems that the sprawl expansion in these districts influenced the growth of informal settlements and increase of crimes. This phenomenon could trigger negative environmental and socio-economical impacts in the study area. Hence, the urban management in Mashhad city should control the sprawl expansion in the prone districts by environmental prevention of land use change and land degradation. Keywords Urban Sprawl Model; Shannon's Entropy; Hierarchical Clustering Analysis; Geo-Statistical Indices
\end{abstract}

\section{T A T I O N L I N KS}

[Alsharif \& Pradhan; 2014] Urban sprawl analysis of Tripoli ...; [Barnes, et al; 2001] Sprawl development: Its patterns ...; [Bhatta; 2009] Analysis of urban growth ...; [Burton; 2000] The compact city: Just or just ...; [Chatterjee, et al; 2016] Spatial modeling of urban ...; [Effat \& El Shobaky; 2015] Modeling and mapping of urban ...; [Epstein, et al; 2002] Techniques for mapping suburban ...; [Ewing; 1994] Characteristics, causes, and effects ...; [Ewing; 1997] Is Los Angeles-style sprawl ...; [Fang, et al; 2007] Measuring urban sprawl in ...; [Farnahad Consultant Engineers; 2009] Building and development ...; [Galster, et al; 2001] Wrestling sprawl to the ground ...; [Gillham; 2002] The limitless city: A primer ...; [Helbich \& Leitner; 2010] Postsuburban spatial evolution ...; [Jat, et al; 2006] Assessment of urban growth ...; [Ji, et al; 2006] Characterizing urban sprawl ...; [Joshi, et al; 2006] Simulating the effect of ...; [Malik \& Abdalla; 2017] Agent-based modelling for urban ...; [Mansouri Daneshvar; 2015] Climatic impacts on hydrogeochemical ...; [Meteorological Center of Khorasan Razavi; 2017] Database of Mashhad Synoptic ...; [Mohammady \& Delavar; 2016] Urban sprawl assessment and ...; [Pham, et al; 2011] A case study on the relation between ...; [Poelmans \& Van Rompaey; 2009] Detecting and modelling spatial patterns ...; [Polidoro, et al; 2011] Environmental impacts of urban ...; [Rabbani, et al; 2018] Urban sprawl modeling using statistical ...; [Rafiee, et al; 2009] Simulating urban growth in Mashad ...; [Rahnama \& Abbaszadeh; 2008] A comparative study measuring ...; [Rahnama \& Javan; 2011] Studies on urban landuse planning ...; [Rui; 2013] Urban growth modeling based on ...; [Schneider \& Woodcock; 2008] Compact, dispersed, fragmented ...; [Shahraki, et al; 2014] Spatiotemporal analysis of the physical ...; [Singh; 2014] Urban growth using shannon entropy ...; [Statistical Centre of Iran; 2011] Macro results of statistical ...; [Tewolde \& Cabral; 2011] Urban sprawl analysis and modeling in ...; [Thomas; 1981] Information statistics in ...; [Yu \& Ng; 2007] Spatial and temporal dynamics of urban ...; [Yuan;; 2005] Land cover classification and change analysis ... 


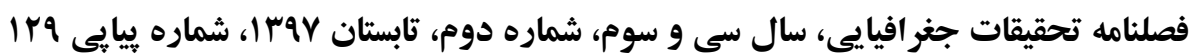

Rabbani Gh. MA

Shafaghi S. PhD

Rahnama M. R. PhD

ghazaleh.rabbani@gmail.com
غزاله ربانى ابو الفضلى، دانشجوى دكترى، گروه جغرافيا و برنامهريزى شهرى، يزوهشكاه شاخص يزوه، اصفهان، ايران

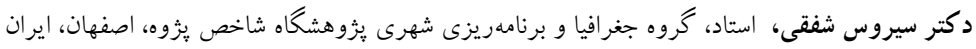

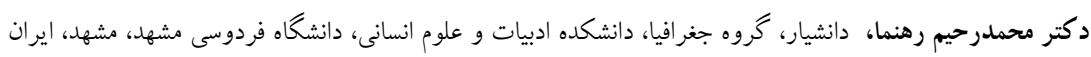

\section{ارزيابى بر اكندهرويى شهرى با استفاده از مدل هاى بر نامهريزى فضايى در مشهد}

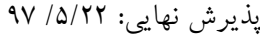

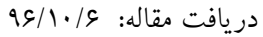

مقدمه: يراكندهرويى شهرى يكى موضوع كليدى در برنامهريزى و سياست گذارى شهرى است كه براى غلبه بر اثرات مخرب

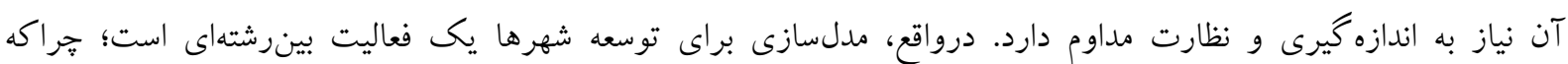

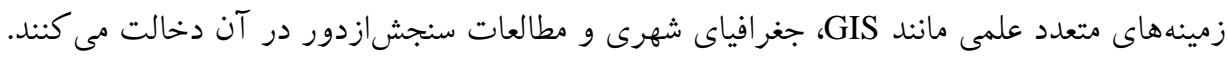
اهداف: هدف اين يزوهش، توليد يك مدل يراكندهرويى شهرى با استفاده از روشهاى برنامهريزى فضايى در شهر مشهد است.

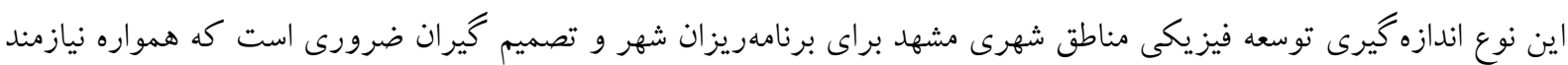

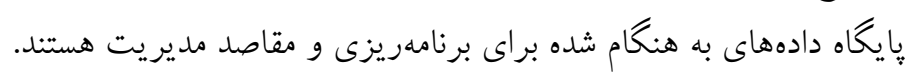

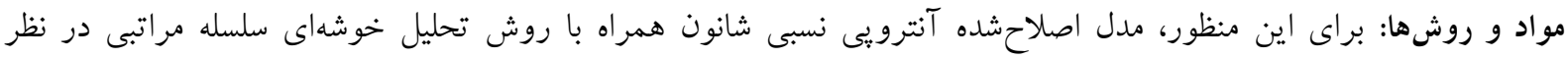

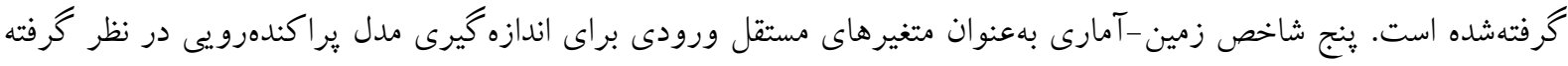

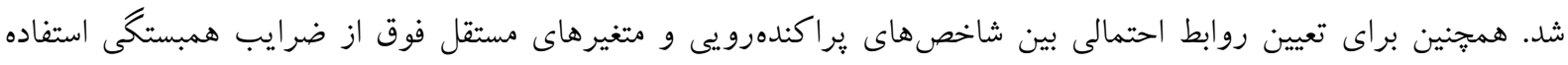

نتيجه گيرى: نتايج نشان داد كه روشهاى اندازهگيرى براكندهرويى شهرى در مدل آنترويى نسبى و تحليل خوشهاى سلسله

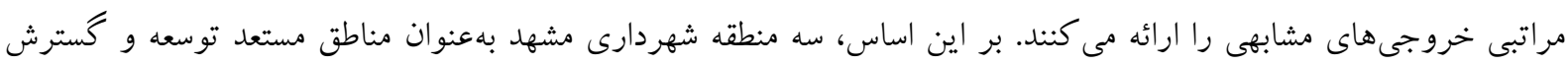

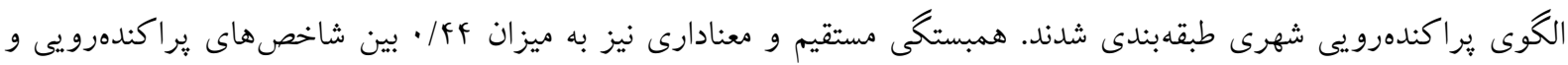

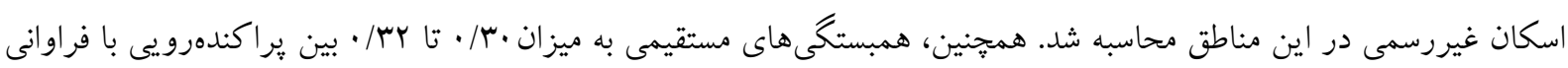

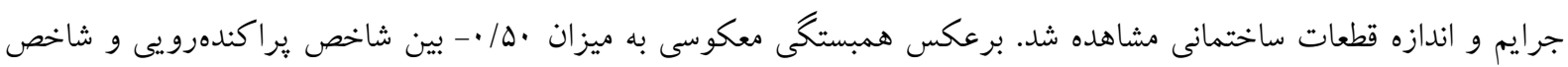

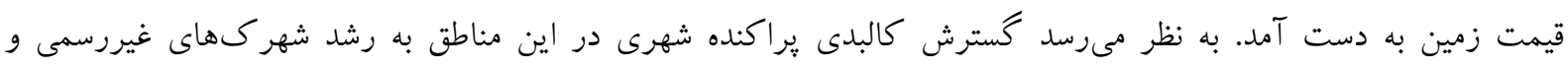
افزايش جرايم منجر شده است. اين يديده مىتواند محرك اثرات منفى و مخرب زيستمحيطى، اجتماعى و اقتصادى باشد.

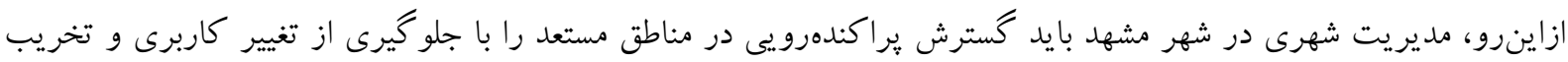
زمين كنترل كند.

وازگًان كليدى: مدل يراكندهرويى شهرى، مدل اصلاحشده آنترويى نسبى شانون، روش تحليل خوشهاى سلسله مراتبى، شاخصهاى زمين- آمارى 
توسعه جشم گير شهرنشينى، همراه با توسعه شهرها ازنظر جمعيت و مساحت و به وجود آمدن كلانشهرها، باعث ايجاد بافت ها و تركيبهاى مختلف شهرى و عوامل ارتباطى و اقتصادى يِيجيدهاى شدهاند كه هرجند واجد بسيارى از مزايا و عوامل رفاهى كرديدهاند، خود مشكلات و معضلاتى را نيز براى شهرنشينان دامن زدهاند كه بهعنوان يكى از مهمترين آنها مىتوان به مسئله يراكنده رويى شهرى اشاره نمود كه موضوع موردمطالعه در اين :يزوهش است. رشد و كسترش يراكنده يكى از اشكال رشد شهر است كه بر اساس عوامل متعددى جون دگرگڤنى بنيان اقتصادى شهر و فراهم شدن امكان بورسبازى زمين، سياست هاى سهل انگارانه شهرسازى و تصميم گيرىهاى ناكهانى براى توسعه شهرى، قوانين و برنامهاى ناكار آمد شهرى شكل

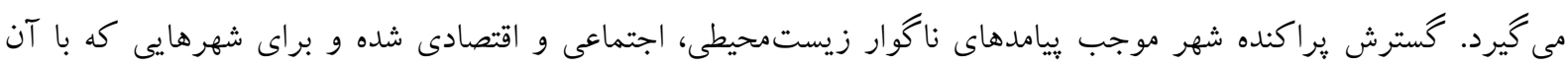
دست در كريباناند به مسئلهاى بغرنج تبديلشده است. يهنههاى شهرى معمولاً رشد سريعترى از جمعيت شهرى را نشان مىدهند Tewolde \& Cabral, 2011) اراضى و منابع قابلدسترس مىشوند (Rafiee, Mahiny, Khorasani, Darvishsefat, \& Danekar, 2009). آنها معمولاً نيازمند روشها و مدلهاى جديد و قابلاعتمادى براى هدايت توسعه پايدار در بستر تغييرات شتابان محيط شهرى هستند ( Pham, (Yamaguchi, \& Bui, 2011 مانند GIS، جغرافياى شهرى و مطالعات سنجشازدور در آن دخالت مى كنند (Rui, 2013). يكى از كارهاى اساسى در مدلسازى توسعه شهر، موضوع اندازه كيرى يراكندكى است. يراكندهرويى شهرى بهعنوان يك مفهوم جندمتغيره است كه

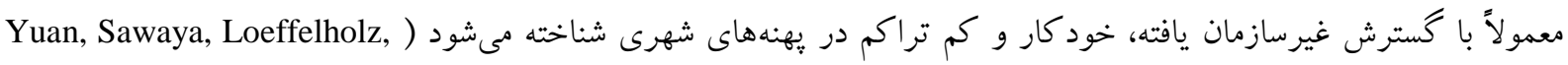
\&auer, 2005 \& آنتروبى شانون كه بهعنوان شاخصى از درجه فشردگى يا يراكندگى فضايى عمل مى كند، مىتواند بهعنوان يك شاخص ثيراكندهرويى، ميزان كسترش شهرها را با بررسى اينكه آيا توسعه زمين شكل تيراكنده يا فشردهاى دارد مشخص كند (Joshi, Guhathakurta, Konjevod, Crittenden, \& Li, 2006). هدف اصلى تحقيق حاضر نيز ساخت يكى مدل يراكندهرويى شهرى براى شهر مشهد است. اندازه گيرى توسعه فيزيكى مناطق شهرى براى برنامهريزان شهر و تصميم كيران

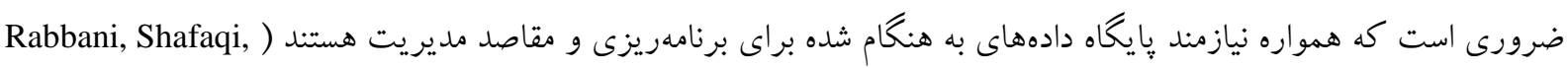
Rahnama, 2018 \& در اين مطالعه شبيهسازى فضايى مدل يراكندهرويى شهرى با استفاده از تكنولوزى GIS انجام مىشود.

كلانشهر مشهد كه دومين شهر :ِرجمعيت كشور و مركز استان خراسان رضوى مىباشد، در دههاى اخير با افزايش سريع

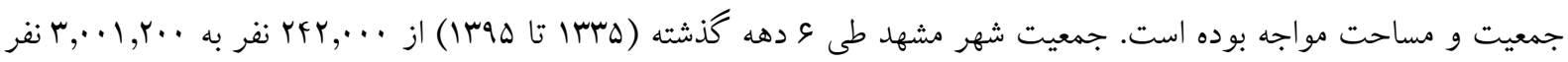

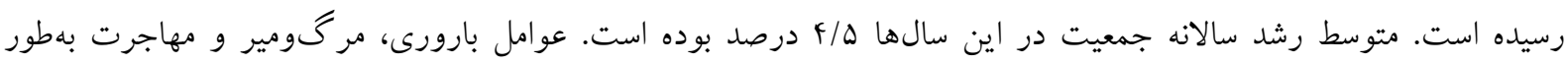
همسو و كاهى ناهمسو، ساختارهاى سنى و جنسى و نيز روند گسترش شهر همكى تأثيرات اساسى و عمدهاى را بر جمعيت شهر

بهجا كذاشتهاند (Rahnama \& Javan, 2011).

ازنظر كالبدى شهر مشهد در طى دو دهه اخير داراى هر دو نوع توسعه ييوسته و ناييوسته بوده است. با بررسى دورههاى

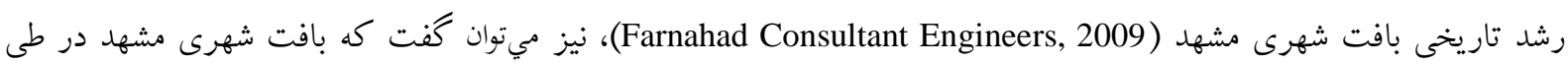

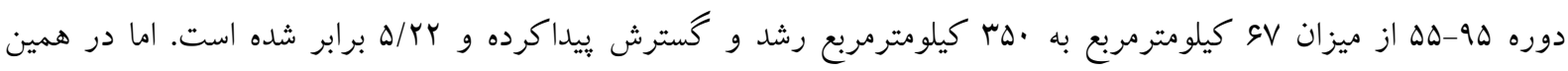

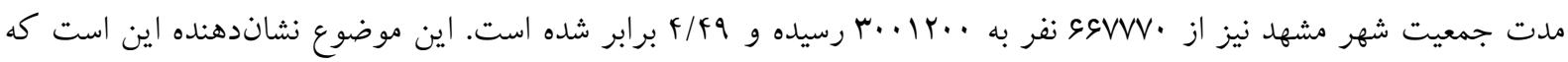


رشد كالبدى شهر در اين مدت بر رشد جمعيتى شهر يِشى گرفته است. همجنين بررسى دقيقتر جمعيت و مساحت در دو دوره اخير سرشمارى (هیr| و هوس|) حاكى از آن است كه نرخ رشد جمعيت مشهد حدود ه/r مىباشد، درحالى كه درصد نرخ رشد مساحت محدوده شهر در اين دوره حدود ه/ مى باشد. درواقع در طى اين ·ل سال مساحت محدوده شهر حدود ب برابر جمعيت شهر رشد داشته است كه مىتوان كفت اين افزايش نسبت رشد مساحت به جمعيت شهر بيش از نياز واقعى شهر بوده كه منجر

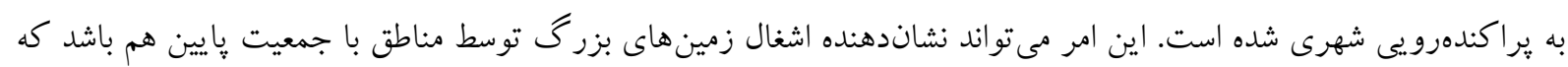
البته خود علاوه بر عدم تعادل فضايى ممكن است معضلات و مخاطرات اجتماعى، اقتصادى و فرهنكى را هم به دنبال داشته باشد. ازاينرو ضرورت دارد تا اين تحقيق بر روى ميزان براكندهرويى شهرى تمركز كند. سؤال اصلى تحقيق اين است كه آيا اندازه كيرى ميزان يراكندهرويى در مناطق شهرى مشهد با به كاركيرى شاخص هاى فضايى مرتبط با اين مفهوم امكانيذير است يا خير؟. در اين راستا تمامى اطلاعات و دادهاى خام و يردازششده فضايى بلدقت در محيط GIS مورد تحليل قرار مى كيرند. درنهايت يكى مدل مفهومى بر مبناى روشهاى آمارى آنترويى نسبى شانون و تجزيهوتحليل خوشهاى سلسله مراتبى براى محاسبه يراكندهرويى فضايى شهر مشهد توليد مىشود.

\section{بيشينه تحقيق}

بر اساس تعريفى از ايوينيخ (199F و 199V) يراكندهرويى بهعنوان يكشكل از توسعه فضايى، عمدتاً در اراضى باز و روستايى در لبه مناطق كلانشهرى يافت مىشود كه داراى تراكمهاى كم، كسترش يراكنده و بىنظم، قطعات تفكيكشده زمين و ... است (Ewing, 1997Ewing, 1994 ;). طبق بيشينه تحقيق، روشهاى آمارى همراه با سنجشازدور و GIS بهطور فزايندهاى در بسيارى از مطالعات يراكندهرويى شهرى استفادهده است (Jat, Garg, \& Khare, 2006). همجنين براى تعيين رابطه بين مناطق تحت توسعه يراكنده و يارامترهاى مختلف توسعه شهرى، از روشهاى آمارى استفادهده است. در سالهاى

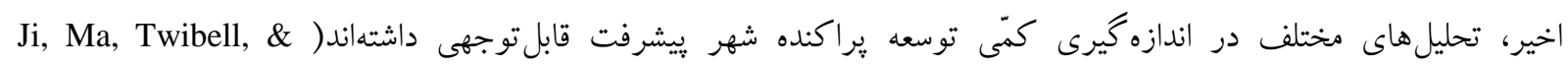
(Schneider \& Woodcock, 2008; Singh, 2014; Yu \& Ng, 2007Underhill, 2006 محاسبه تغييرات فضايى و زمانى :هنههاى ساختهشده و تراكم جمعيت مىباشد (Effat \& El Shobaky, 2015). يهنه ساختهشده

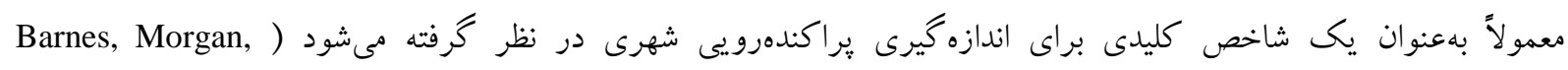
(Epstein, Payne, \& Kramer, 2002Roberge, \& Lowe, 2001 روش هاى مناسب كمّى و آمارى همجون آنتروبى شانون، شاخص لكه كذارى فضايى، معيارهاى جشمانداز، خوشهبندى سلسله مراتبى، تجزيهوتحليل رگرسيونى و ... است. آنترويى شانون بهعنوان يكى روش يذيرفته در ارزيابى يراكندهرويى شهرى در

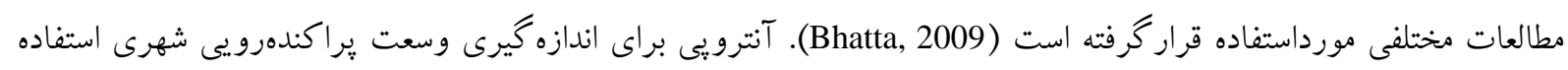
مىشود كه مىتواند مستقيماً در محيط GIS به انجام برسد (Chatterjee, Chatterjee, \& Khan, 2016). جمعبندى بيشينه

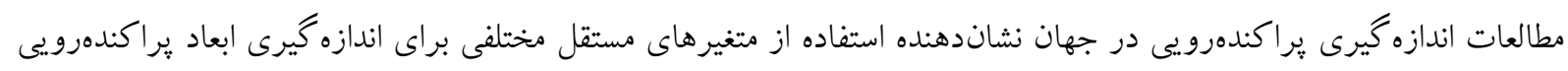
است كه عمدتاً شامل تراكم ساختمانى و جمعيتى، تداوم و تمركز فضايى، خوشهاى بودن يا مركزيت فضايى، اختلاط و همجوارى كاربرى ها مىباشند. در اكثر تحقيقات الكوهاى رشد و توسعه شهرى در بازههاى زمانى خاص موردبررسى قرارگرفته است. درنهايت با استفاده از سيستم اطلاعات جغرافيايى ميزان رشد يراكنده شهر محاسبه مىشوند. 


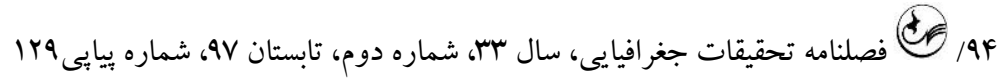
مبانى نظرى الكوى پراكندهرويى شهرى ابتدا در كشورهاى توسعهيافته به علت استفاده زياد از اتومبيل شخصى و حومهنشينى به وجود آمد و امروزه در بسيارى از هسته هاى شهرى كشورهاى درحالتوسعه ديده مىشود ) Shahraki, Kazemzadeh, \& Badami,

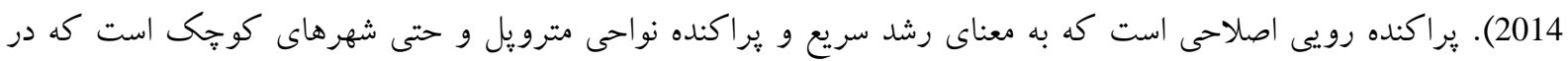

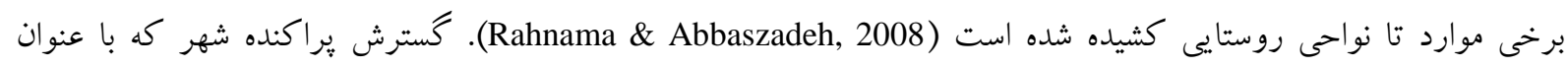

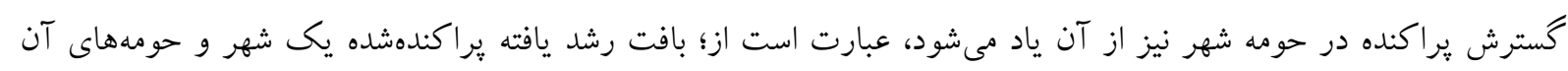

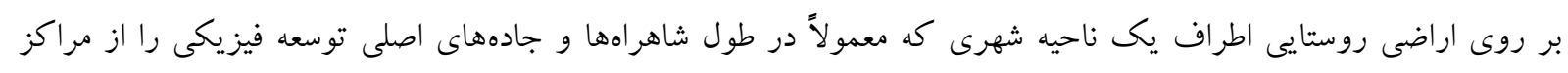

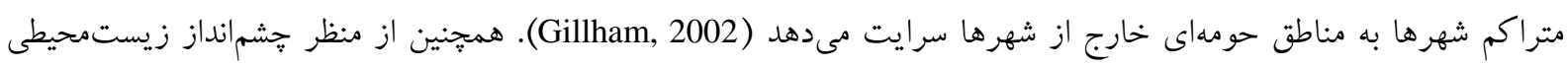

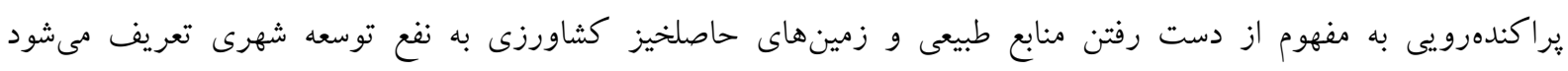

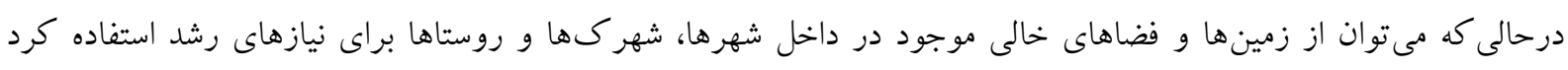

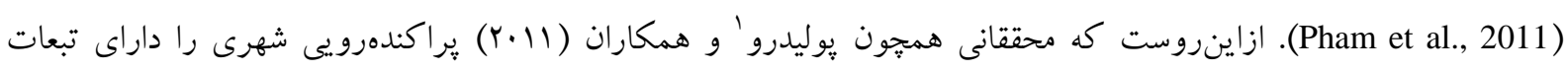

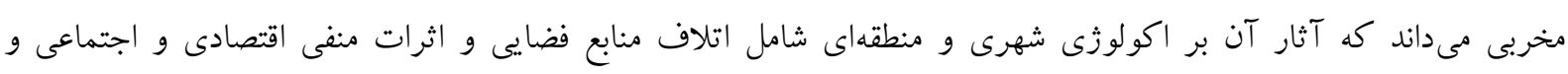
سلامتى سا كنان شهرها است (Polidoro, de Lollo, \& Barros, 2011).

روش تحقيق

معرفى محدوده مطالعه

محدوده موردمطالعه اين تحقيق را شهر مشهد تشكيل مىدهد. شهر مشهد بهعنوان مركزيت استان خراسان رضوى در شمال

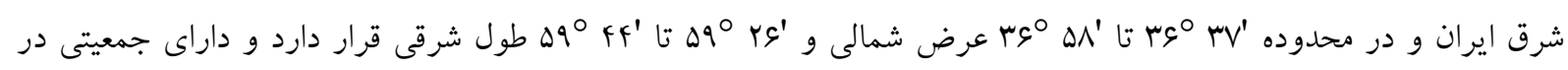

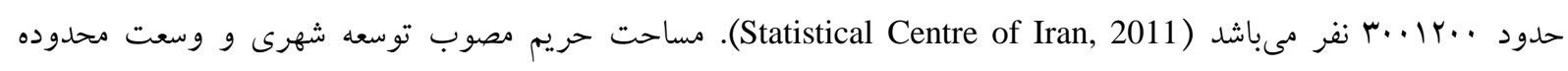

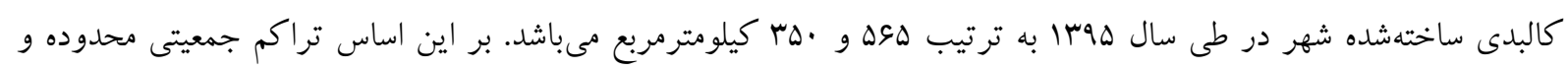

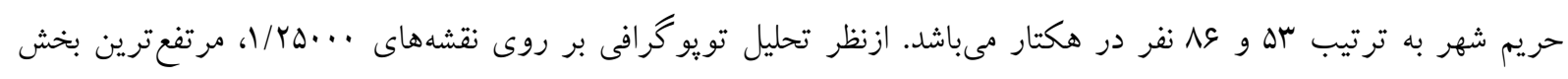

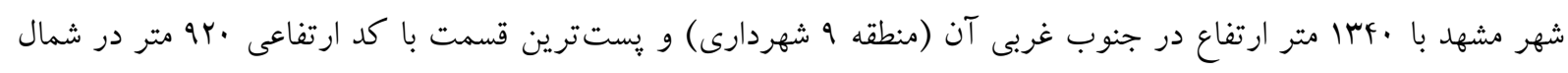

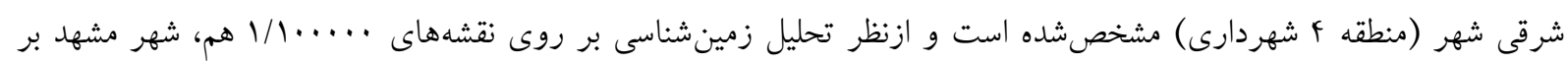

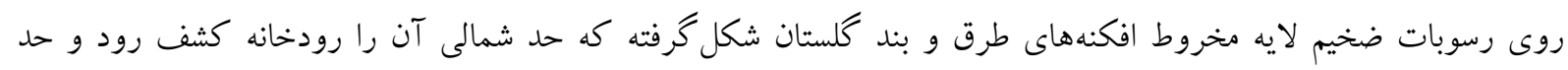

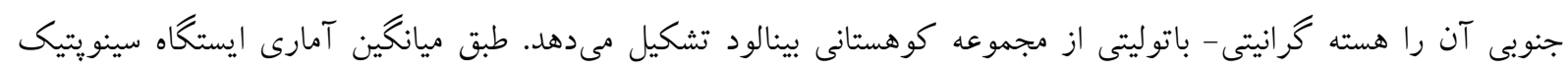

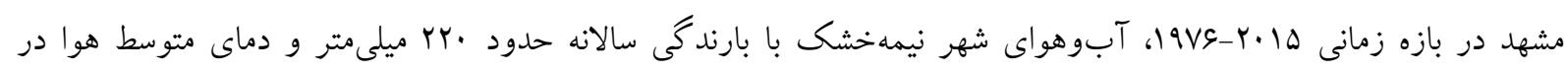

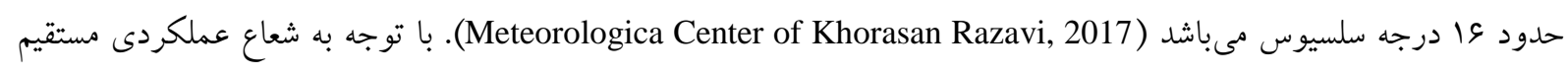
شهر مشهد، و متناسب با رشد فضايى شهر، محدوده خدماتى مناطق شهردارى تدقيق شدهاند بهطورى كه در سال هوسا شهر مشهد

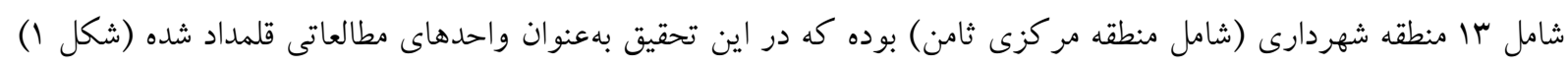
و نتايج تحقيق به تفكيك آنها ارائه مى گردد. 


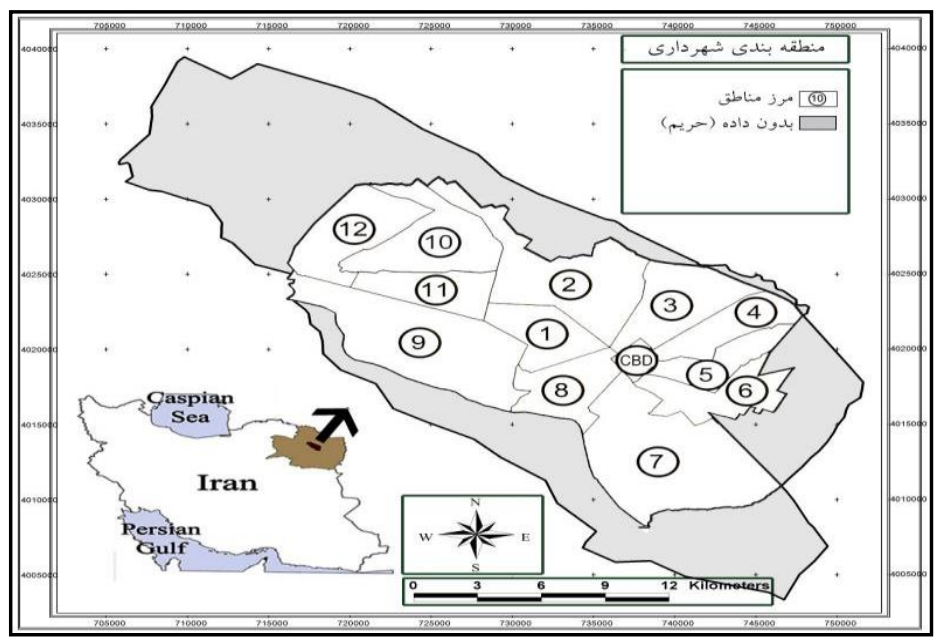

شكل ا - مرزبندى مناطق شهردارى مشهد

دادههاى خام آمارى مربوط به مساحت منطقه، جمعيت، وسعت اراضى ساختهشده، وسعت فضاهاى سبز و باز، وسعت

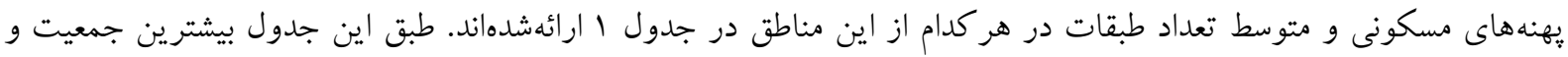

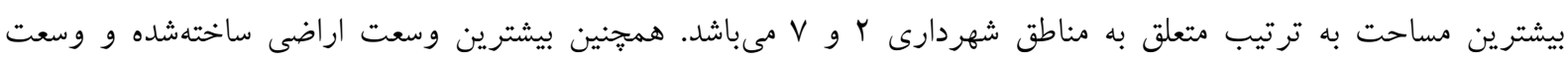

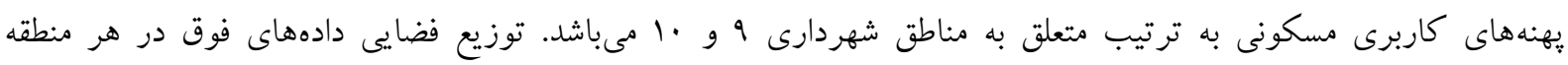

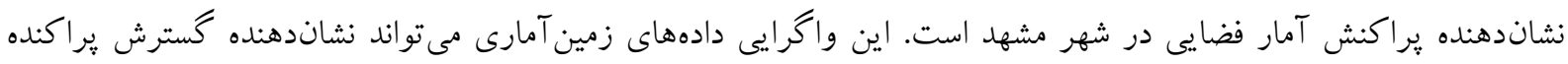
فضايى شهرى باشد كه در اين مقاله بيشتر مطالعه خواهد شد.

جدول 1- دادههاى خام آمارى مساحت منطقه، جمعيت، وسعت اراضى ساختهشده، وسعت فضاهاى سبز

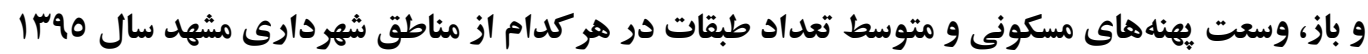

\begin{tabular}{|c|c|c|c|c|c|c|}
\hline متوسط تعداد & 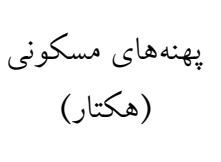 & سضاهاى باز و (هكتار) & (هاختهشده & كل مساحت & جمعيت & شهردارى منطقه \\
\hline$r / l$ & $\Delta \Delta V$ & s广 & $\Delta F$. & IfVA & $|V s| \cdot f$ & 1 \\
\hline$r / s$ & IFF & TrVA & IroT & וس ו" & $F \wedge \Delta \wedge \mu r$ & r \\
\hline$r / \pi$ & IVF & IrEs & $\Delta r q$ & MI.F & Mrt. & $r$ \\
\hline$r / r$ & ITV & VQq & sin & IrWV & rFFGFF & f \\
\hline$r / T$ & rVV & VID & FIN & $11 \pi \pi$ & ISMVE & Q \\
\hline$r / r$ & Yls & qr. & SSA & 1091 & roTqG & s \\
\hline $1 / \mathrm{V}$ & rI. & rT. $\Delta$ & $19 / 4$ & DIM & r.s9s1 & v \\
\hline$r / s$ & TEV & Ir.r & F.I & 19.4 & $q f . F$. & $\wedge$ \\
\hline$r / 1$ & $a \cdot V$ & $r \cdot \Delta f$ & rETS & FSA. & r.. rFs & 9 \\
\hline$r / \Lambda$ & $\Delta S V$ & Irq4 & $11 M$ & rFAl & TEFATM & 1. \\
\hline$r / f$ & $\Delta H_{F}$ & $V T_{F}$ & sqf & IFYN & IGKYKM & 11 \\
\hline$r / r$ & 11. & IVTS & FYF & rifq & ragrs & Ir \\
\hline$r / 1$ & 98 & $1 \Delta S$ & 191 & rof & ISMF & ثامن \\
\hline
\end{tabular}




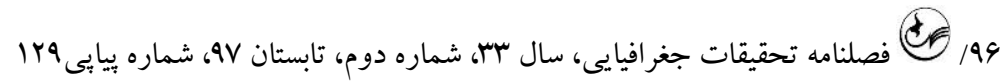
مدل مفهومى ثراكندهرويى شهرى

تاكنون مطالعات زيادى بر روى ابعاد فيزيكى براكندهرويى صورت يذيرفته ولى اندازهيرى ڤبراكندهرويى شهرى با

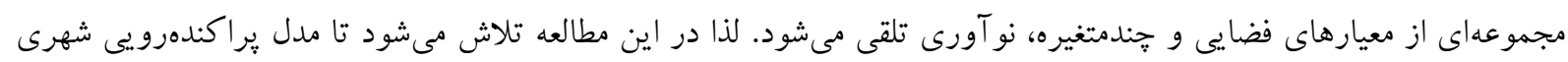

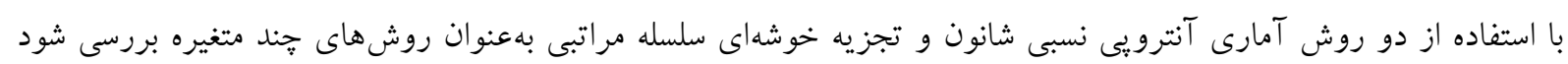

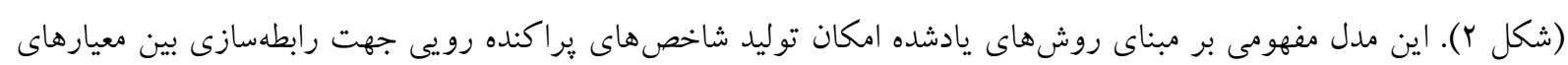
مختلف را نيز فراهم مى كند.

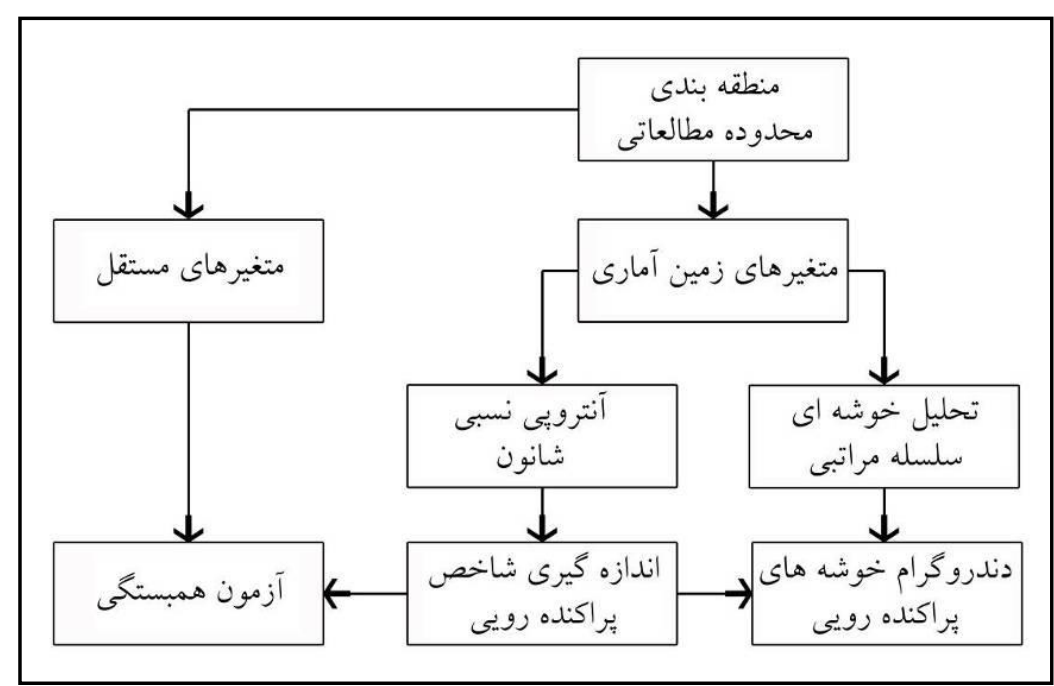

شكل r- دياكرامى از مدلسازى يراكندهرويى شهرى

متغيرهاى تحقيق نيز بر اساس بيشينه تحقيق، كارهاى آمارى انجامشده در اين زمينه و اطلاعات قابلدسترسى براى مطالعه

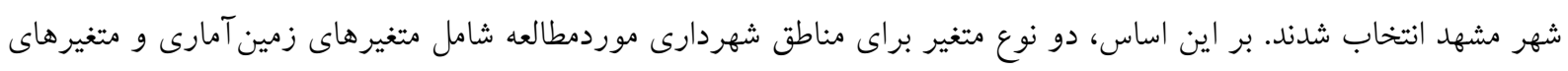

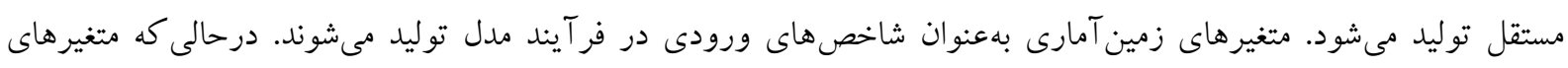

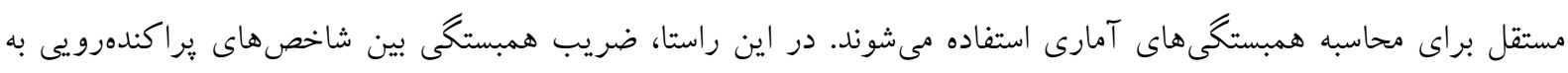

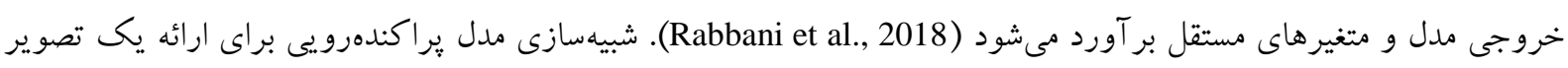

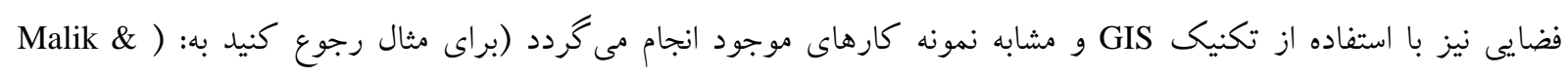
.(; Mohammady \& Delavar, 2016Abdalla, 2017

\section{معرفى متغيرهاى زمين آمارى}

ينج متغير زمين آمارى از سنجهاى ورودى مدل يراكندهرويى بر مبناى مناطق شهردارى مشهد در نظر گرفته شدند كه شامل

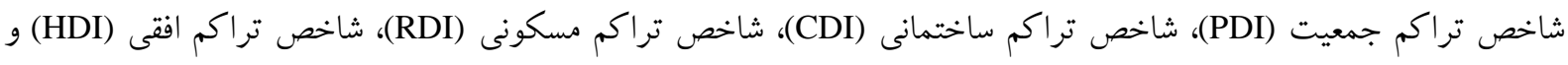

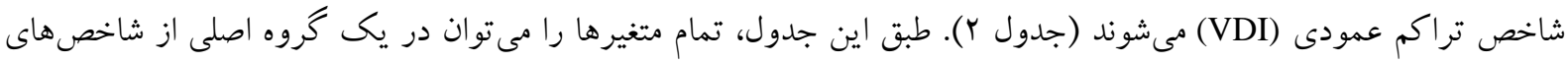

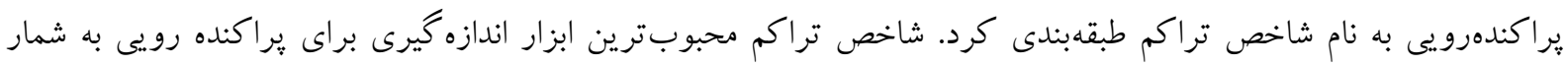

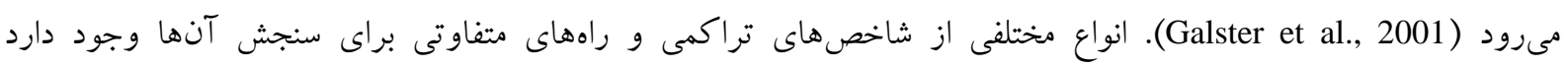


جدول r - متغيرهاى زمين آمارى مربوط به شاخص هاى تراكم جمعيت، تراكم ساختمانى،

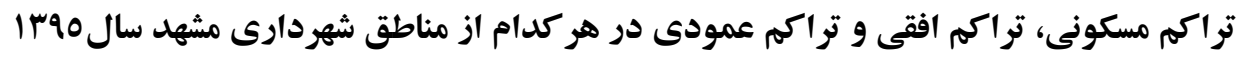

\begin{tabular}{|c|c|c|c|c|c|}
\hline تراكم عمودى (درصد) & تراكم افقى & تراكم مسكونى (درصد) & تراكم ساختمانى & (نراكم جمعيت & منطقه شهردارى \\
\hline IVS & $\Delta V$ & $\mu \wedge$ & ITY & 119 & 1 \\
\hline १V & rV & $r$ & $\Delta q$ & IrF & $r$ \\
\hline$q r$ & f. & $\wedge$ & sद & lor & $r$ \\
\hline $1 . r$ & ta & 1. & $\wedge 1$ & IVA & f \\
\hline ᄉI & rV & YF & $\Delta \Lambda$ & $1 F 9$ & a \\
\hline$q r$ & Fr & If & Vr & 169 & s \\
\hline so & r & f & GY & f. & V \\
\hline so & ro & IV & سץ & 09 & $\wedge$ \\
\hline IVF & $\Delta S$ & 11 & $\mid r \Lambda$ & sf & 9 \\
\hline IrF & $k \wedge$ & r & $q r$ & $1 . V$ & 1. \\
\hline 1so & 49 & rV & 90 & Ira & 11 \\
\hline gr & $r$. & $\wedge$ & ro & 11 & ir \\
\hline IVT & $\Delta S$ & TV & ITV & FA & ثامن \\
\hline
\end{tabular}

تراكم بهعنوان نسبت بين مقدار يك داده خام و مساحت آن يا مساحت زمينههاى ديكرى كه بر روى آن قرار دارد،

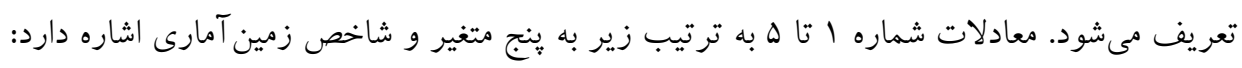

$$
P D I=\frac{P}{A_{t}}
$$

در رابطه فوق P مقدار جمعيت است، A كل مساحت منطقه به واحد هكتار است و PDI شاخص تراكم جمعيت به واحد نفربر هكتار براى هر منطقه شهردارى است.

$$
C D I=\frac{A_{b} \times 100}{A_{o}}
$$

در رابطه فوق A مساحت اراضى ساختهشده به واحد هكتار است، A مساحت فضاهاى سبز و باز به واحد هكتار است و شاخص تراكم ساختمانى به واحد درصد براى هر منطقه شهردارى است.

$$
R D I=\frac{A_{r} \times 100}{A_{t}}
$$

در رابطه فوق A مساحت اراضى كاربرى مسكونى به واحد هكتار است، A A S مساحت منطقه به واحد هكتار است و شاخص تراكم مسكونى به واحد درصد براى هر منطقه شهردارى است.

$$
H D I=\frac{A_{b} \times 100}{A_{t}}
$$

در رابطه فوق A A A ماحت اراضى ساخته شده به واحد هكتار است، A كل مساحت منطقه به واحد هكتار است و HDI شاخص تراكم افقى به واحد درصد براى هر منطقه شهردارى است.

$$
V D I=\frac{F \times A_{b} \times 100}{A_{t}}
$$




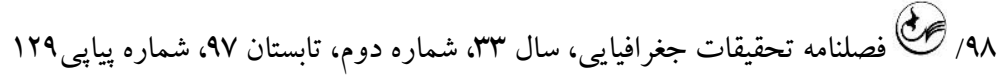

در رابطه فوق F ميانخين منطقهاى تعداد طبقات ساختمانى است، A مساحت اراضى ساختهشده به واحد هكتار است، A مساحت منطقه به واحد هكتار است و VDI شاخص تراكم عمودى به واحد درصد براى هر منطقه شهردارى است. مقادير بالاتر

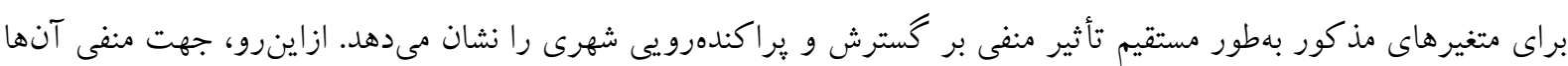

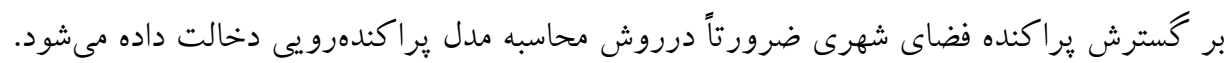

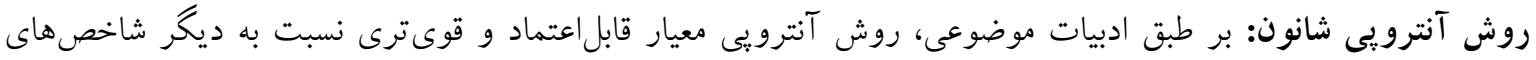

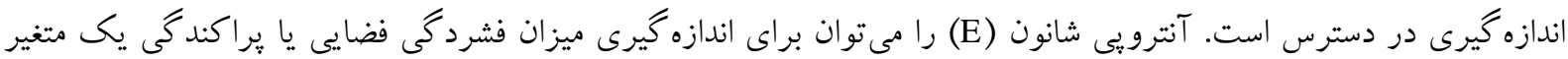
جغرافيايى (xi) در بين مناطق مختلف مورداستفاده قرارداد (Thomas, 1981). ضريب آنترويى شانون (E) در شكل معمول آن ين ينائي بر مبناى معادله 8 بر آورد مىشود:

$$
E=-\sum_{i=1}^{n} P_{i} \times \log _{e} P_{i} \quad \text { (معادله }
$$

در رابطه فوق Pهم نسبى از يديدهاى است كه در منطقه شماره i رخ مىدهد و توسط معادله شماره V محاسبه مىشود، ارزش مشاهدهده از يديدهاى رخداده در منطقه شماره i است و n نيز تعداد كل مناطق شهردارى است كه در تحقيق حاضر معادل rا مىباشد.

$$
P_{i}=\frac{x_{i}}{\sum_{i=1}^{n} x_{i}}
$$

آنترويى نسبى مى تواند براى مقياس گذارى مقادير آنترويى از · تا ا محاسبه شود. بر اساس روش كار توماس (1911)، آنترويى نسبى (Hn) براى n تعداد از مناطق جغرافيايى مى تواند بهصورت زير محاسبه شود (Thomas, 1981):

$$
H_{n}=\frac{E}{\log _{e}(n)}
$$

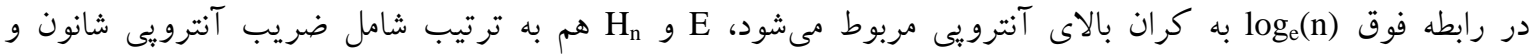

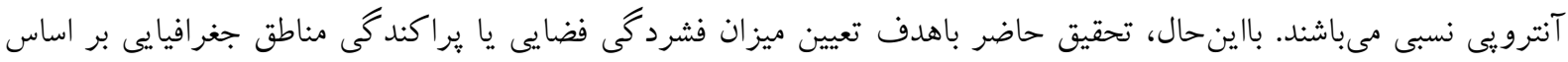

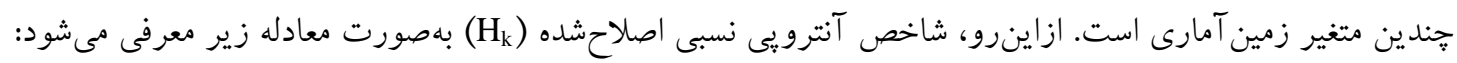

$$
H_{k}=\left[-\sum_{i=1}^{k} P_{i} \times \log _{e} P_{i}\right] / \log _{e}(k)
$$

در رابطه فوق k تعداد كل متغيرهاست (در تحقيق حاضر معادل ه) و تحقيق حاضر معادل 9.\&/1 محاسبه مىشود. در اين تحقيق، ه/• (براى هر منطقه) بهعنوان حد آستانه آنترويى محسوب مىشود.

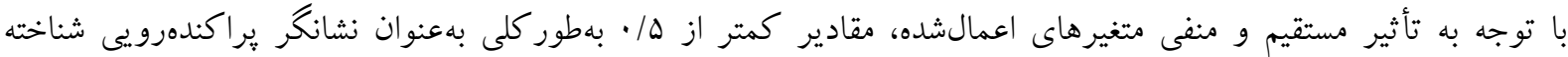

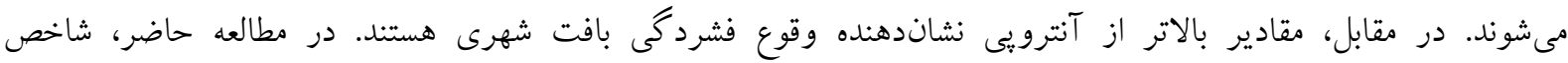

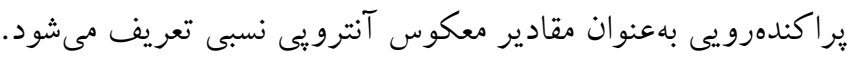
تحليل خوشهاى سلسله مراتبى: تجزيهوتحليل خوشهاى سلسله مراتبى (HCA) و تجزيهو تحليل عوامل اصلى (PCA) براى

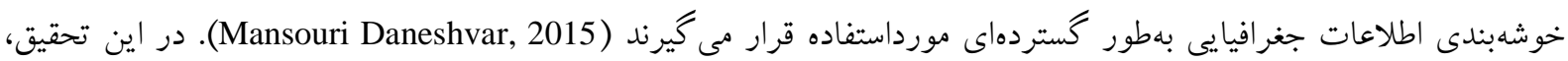

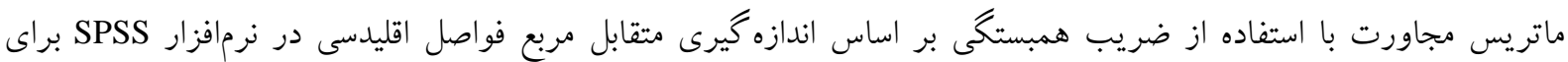

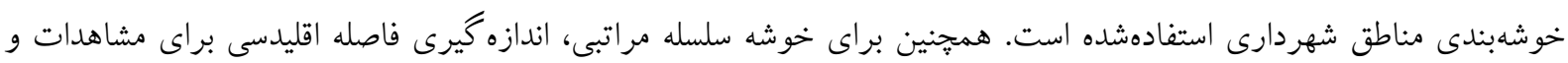

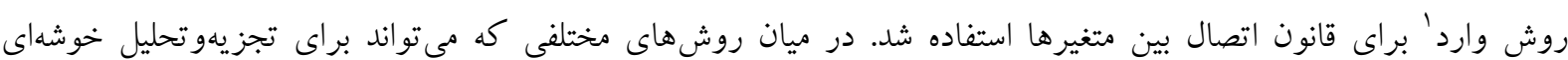


سلسله مراتبى اجرا شود، روش وارد گروهبندى متمايزى را براى دادهاى مورداستفاده فراهم مى كند. نهايتاً در مطالعه حاضر،

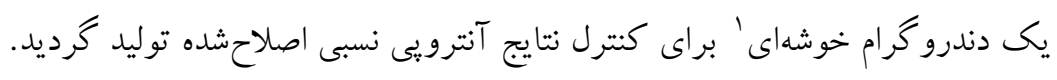

\section{معرفى متغيرهاى مستقل تحقيق}

در اين تحقيق، بنج متغير مستقل شامل سكونتخاههاى غيررسمى، اندازه قطعات ساختمان، سرانه مالكيت خودرو، قيمت زمين

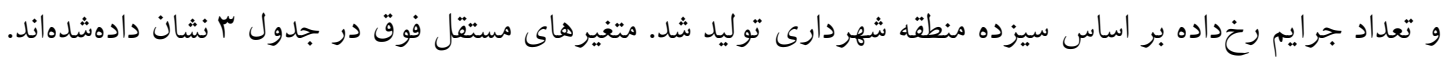

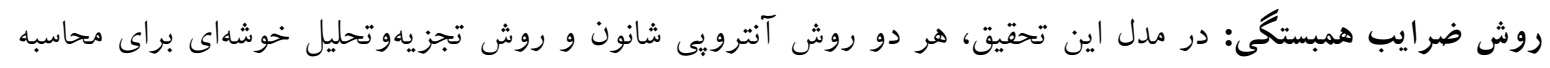

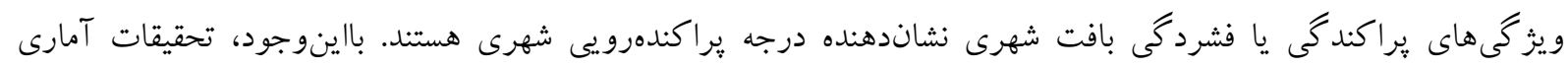

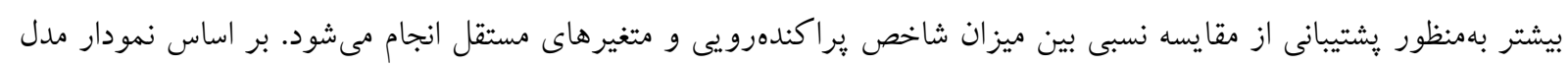

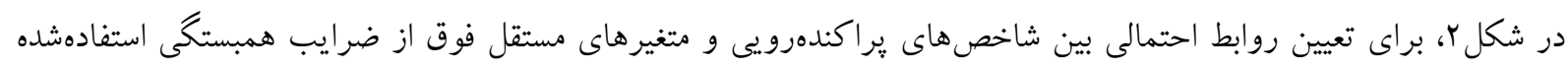

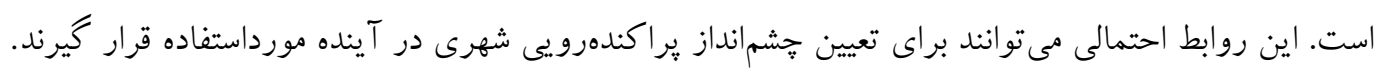

جدول بـ متغير هاى مستقل سكونتعاههاى غير رسمى، اندازه قطعات ساختمان، سر انه مالكيت خودرو، قيمت زمين، و تعداد جرايم رخداده در هر كدام از مناطق شهردارى مشهد سال

\begin{tabular}{|c|c|c|c|c|c|}
\hline 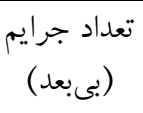 & 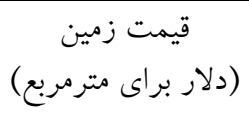 & خرانه مالكيت & $\begin{array}{c}\text { قطعات ساختمانى (مترمربع) } \\
\text { قاخع }\end{array}$ & غيررسمى (هكتار) & شنطردارى \\
\hline IEF. & $\Delta \cdots$ & $\cdot / \Lambda \mathrm{V} \Lambda$ & 190 & . & 1 \\
\hline . & r... & $\cdot / 090$ & MF. & $\mathrm{rqD}$ & r \\
\hline $19 \cdot 0$ & $10 \ldots$ & سז/ & $r \cdot \Delta$ & qVD & r \\
\hline$M \mu$. & $10 \ldots$ & - / Tra & IV. & FV. & f \\
\hline$\Delta F \Delta$ & $1 \ldots$ & . / MTF & $r V$. & 811 & $\Delta$ \\
\hline ITYD & $1 \ldots$ & טاس/. & $r \Delta \Delta$ & $V \cdot r$ & s \\
\hline$r \& 90$ & ra... & $\cdot / V \Psi q$ & $v \cdot \Delta$ & DrT & V \\
\hline$\Lambda \notin \Delta$ & Fa... & $\cdot / F \Delta Q$ & 190 & r. & $\wedge$ \\
\hline qVa & Fa... & . IFET & $\Lambda_{\Delta}$. & . & 9 \\
\hline IVr. & r... & $\cdot / Y \mid I$ & Fa. & $1 \cdot 1$ & 1. \\
\hline r.. & ra... & $\cdot / F V V$ & rVa & . & 11 \\
\hline $1 \% \ldots$ & $1 \cdots$ & - / FrY & 111. & · & Ir \\
\hline 990 & $\Delta \Delta \ldots$ & . MFa & $1 \Lambda$. & . & ثامن \\
\hline
\end{tabular}

بحث و نتايج

بر آورد شاخص هاى زمين آمارى

بر اساس معادلات ا تا ها هنبج شاخص زمين آمارى موردنياز تهيهشده و در شكل ب ارائه گرديدهاند. در اين راستا، تمام

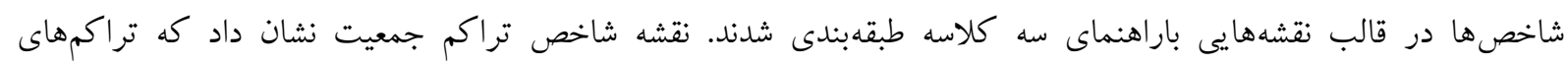

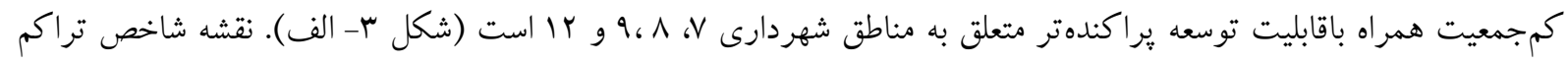

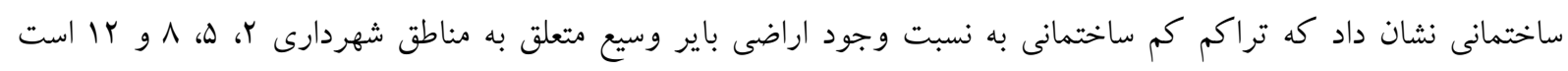

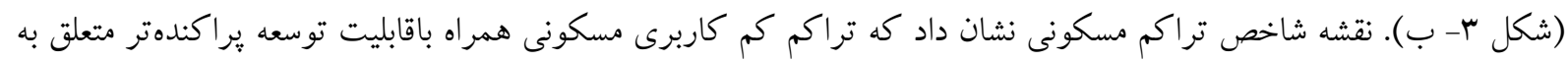


.,...

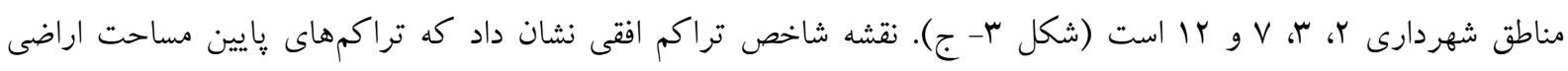

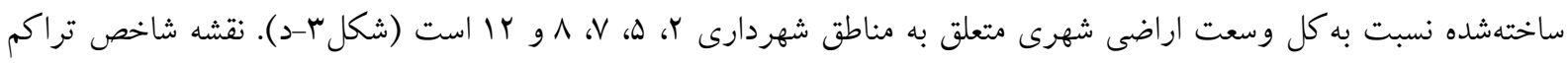

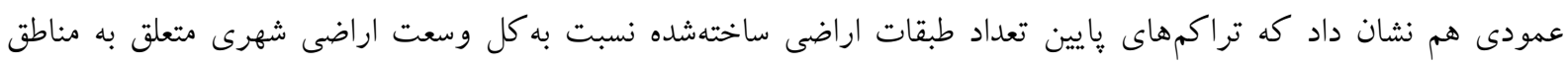

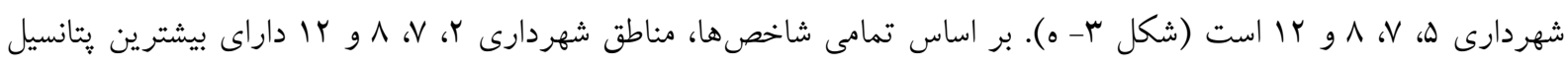
رشد يراكنده در محدوده مطالعاتى مىباشند.

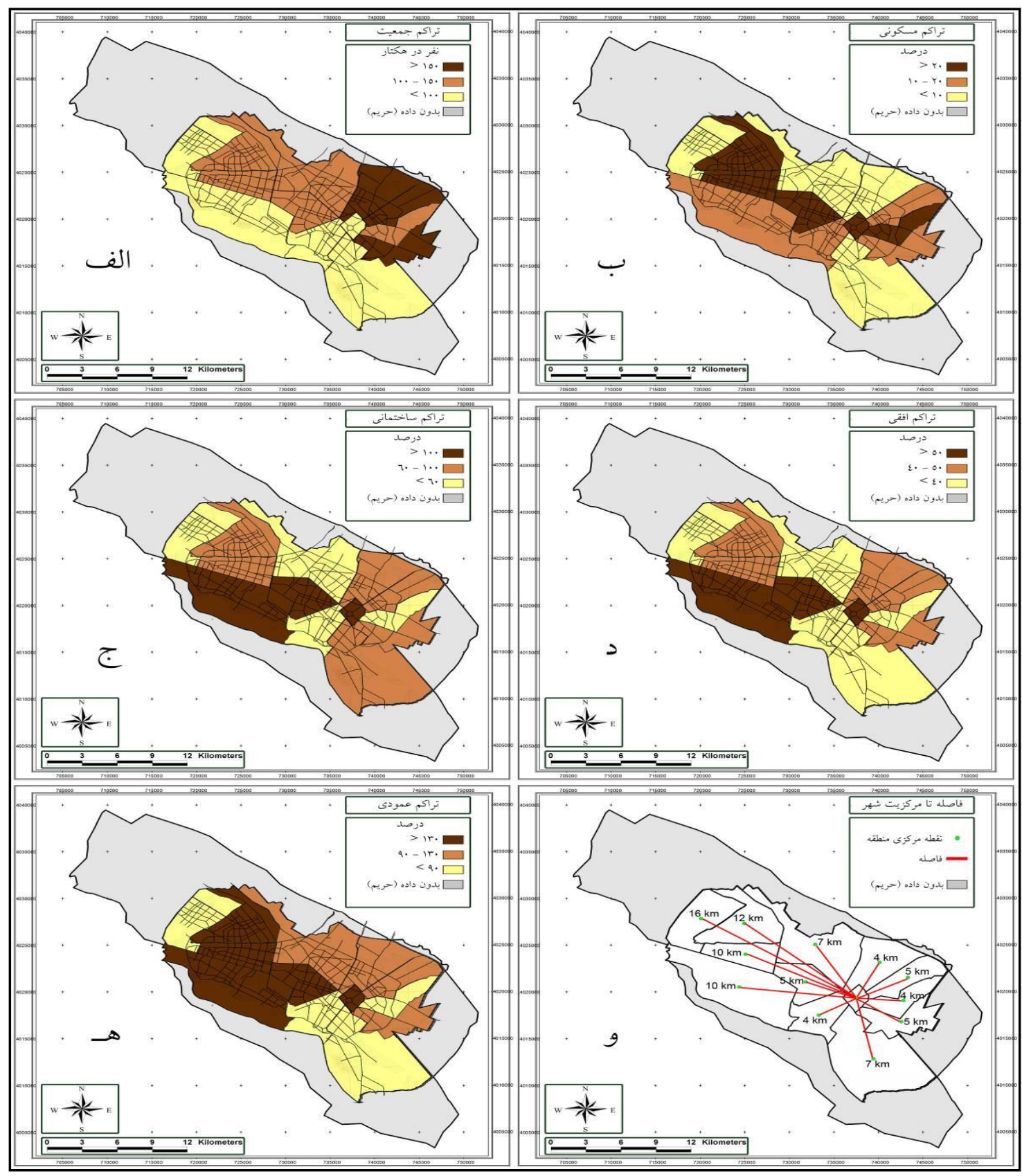

شكل r- توزيع فضايى شاخصهاى براكندهرويى: الف) شاخص تراكم جمعيت، ب) شاخص تراكم ساختمانى،

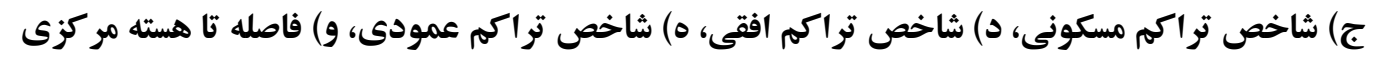

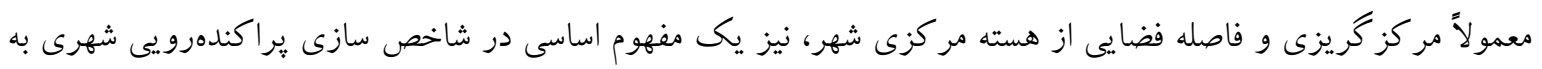

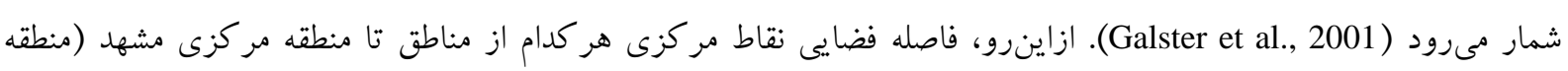




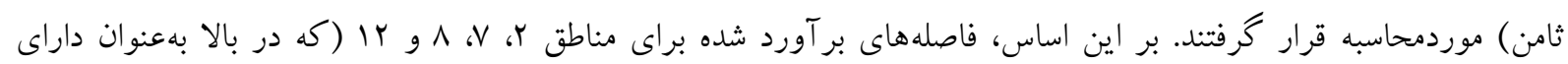

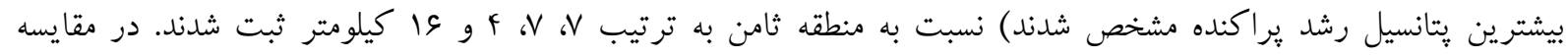

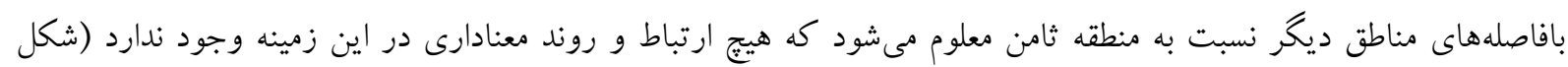

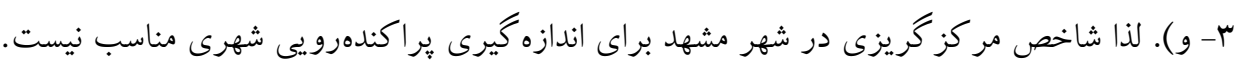
اندازه كيرى شاخص براكندهرويى شهرى

بر اساس معادله 9، بر آورد آمارى اجزاى آنترويى شانون براى هر كدام از مناطق شهردارى مشهد در جدول \& محاسبهشه

جدول ع - ارزيابى آمارى اجزاى آنترويى شانون در هر كدام از مناطق شهردارى مشهد

\begin{tabular}{|c|c|c|c|c|c|c|c|c|c|c|c|}
\hline \multicolumn{2}{|c|}{ تراكم جمعيت } & \multicolumn{2}{|c|}{ تراكم ساختمانى } & \multicolumn{2}{|c|}{ تراكم مسكونى } & \multicolumn{2}{|c|}{ تراكم افقى } & \multicolumn{2}{|c|}{ تراكم عمودى } & \multirow{2}{*}{ نسبى شانون } & \multirow{2}{*}{ شهردارى } \\
\hline $\mathrm{Pi}$ & Pi $\times$ Loge Pi & $\mathrm{Pi}$ & PixLoge Pi & $\mathrm{Pi}$ & PixLoge Pi & $\mathrm{Pi}$ & PixLoge Pi & $\mathrm{Pi}$ & PixLoge Pi & & \\
\hline .1 .9 & $-\cdot|r|$ &.$/ 1 \pi$ &.$- / r \varepsilon$ &.$/ \mathrm{VV}$ & $-\cdot / \mu$. &.$/ 1$ & $-\cdot / K r$ &.$/ 1 Y$ & $-\cdot / r \Delta$ & $\cdot / V \wedge s$ & 1 \\
\hline$\cdot 11$ & $-\cdot / r \mu$ & $.1 \cdot 9$ &.$- / 18$ &.$/ \cdot 1$ &.$- / .9$ & $\cdot / \cdot V$ & $-\cdot / 1 \Lambda$ & $\cdot / \cdot \mathrm{V}$ & $-\cdot / 11$ & $\cdot / \Delta \cdot r$ & r \\
\hline.$/ 11$ & $-\cdot / r \Delta$ &.$/ \cdot 8$ & $-\cdot / 1 \wedge$ & $\cdot / \cdot f$ &.$- / 1 r$ & $\cdot / \cdot V$ &.$- / 19$ &.$/ \cdot 8$ &.$- / 1 V$ & - /DSY & $r$ \\
\hline . & $-\cdot / T V$ & $\cdot / \cdot 1$ & $-\cdot / r$ & $\cdot / \cdot f$ &.$- / 1 f$ & $\cdot / \cdot 1$ & $-\cdot / r$ & $\cdot / \cdot \mathrm{V}$ &.$- / 19$ & $\cdot / 81 \wedge$ & f \\
\hline.$/ 11$ &.$- / K F$ &.$/ \cdot 8$ &.$- / 18$ &.$/ 11$ & $-\cdot / Y F$ & $\cdot / \cdot V$ & $-\cdot / 1 \wedge$ & $\cdot / \cdot 0$ &.$- / 18$ &.$/ 811$ & 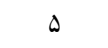 \\
\hline.$/ 1 r$ & $-\cdot / T_{\Delta}$ & $\cdot / \cdot v$ &.$- / 19$ &.$/ .5$ & $-\cdot / \mathrm{VV}$ & $\cdot / \cdot 1$ & $-\cdot / r$. &.$/ .8$ & $-\cdot / \mathrm{IV}$ & $\cdot / 8 \cdot 1$ & $\varepsilon$ \\
\hline$\cdot / \cdot r$ &.$- / 1$ & $\cdot / \cdot 8$ &.$- / 1 \mathrm{~V}$ & $\cdot / \cdot r$ & $-\cdot / \cdot V$ & $\cdot / \cdot V$ &.$- / 1 \Lambda$ & $\cdot / \cdot f$ &.$- / 1 f$ & $\cdot / F \mid f$ & v \\
\hline$\cdot / \cdot F$ &.$- / 1 f$ & . &.$- / 11$ & $\cdot 1 \cdot 1$ & $-\cdot / r$. & $\cdot / \cdot 0$ &.$- / 1 f$ & $\cdot / \cdot F$ &.$- / I f$ &.$/ F F V$ & $\wedge$ \\
\hline$\cdot 1 \cdot \Delta$ &.$- / 1 F$ &.$/ 1 r$ &.$- / 48$ & $\cdot / \cdot 0$ &.$- / 10$ &.$/ 1$ & $-\cdot / r \mu$ &.$/ 1 \mathrm{r}$ & $-\cdot / r \Delta$ & . ISFT & 9 \\
\hline$\cdot / \cdot 1$ & $-\cdot / r$ & .1 .9 & $-\cdot / r r$ &.$/ 1$ & $-\cdot / r \mu$ & .1 .9 & $-\cdot|r|$ & .1 .9 &.$- / r r$ &.$|s V|$ & 1. \\
\hline$\cdot 11$ & L & .1 .9 &.$- / Y r$ & $\cdot / \mathrm{VV}$ & $-\cdot / \mu$ &.$/ .9$ & $-\cdot / r r$ & .111 & $-\cdot / F_{F}$ & . /Va. & 11 \\
\hline.$/ \cdot 1$ & -.1 .9 & $\cdot / \cdot r$ & -.1 .9 & $\cdot / \cdot f$ &.$- / 1 r$ & $\cdot / \cdot 4$ &.$- / M r$ & $\cdot / \cdot F$ &.$- / 1 \pi$ & - / TYF & ir \\
\hline$\cdot / \cdot f$ &.$- / 1 r$ &.$/ 1 r$ &.$- / Y \varepsilon$ &.$/ 1 r$ & $-\cdot / r \varepsilon$ & $\cdot 11$ & $-\cdot / r \mu$ & $\cdot / 1 r$ & $-\cdot / r \Delta$ & - /sqr & ثامن \\
\hline
\end{tabular}

آنترويى نسبتى اصلاحشده در اين جدول نشان مىدهد كه بيشترين يراكندهرويى شهر در مناطق Yl، ل و ^ ^به ترتيب با مقادير

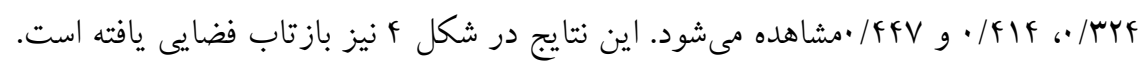

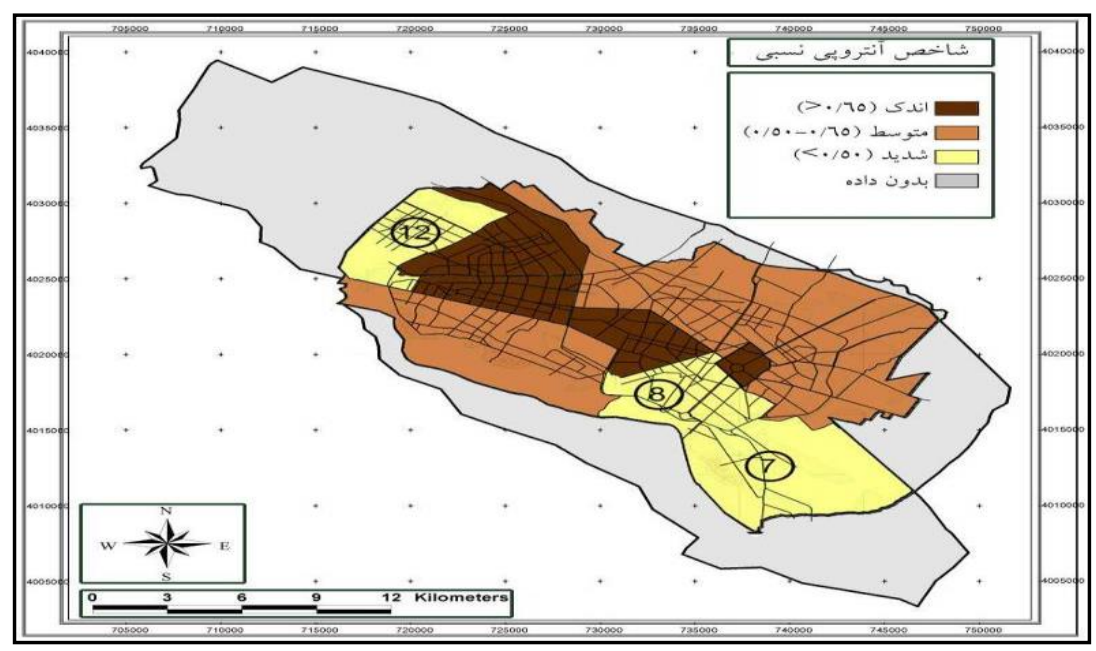

شكل ع- توزيع شاخص آنترويى نسبى در سه كلاسه بر اساس هر منطقه شهردارى مشهد

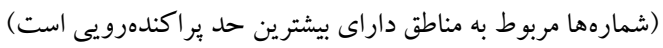




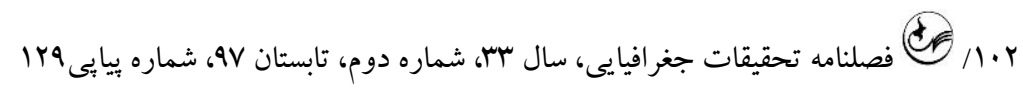
بر اين اساس مناطق يادشده در بخشهاى شمال غربى و جنوب شرقى شهر مشهد واقعشداند. بر اساس مستندات قانونى

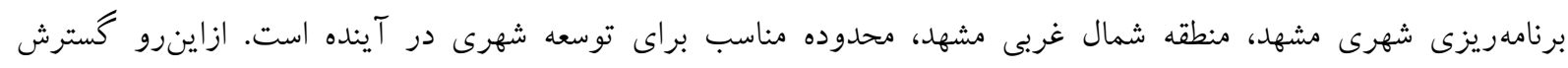

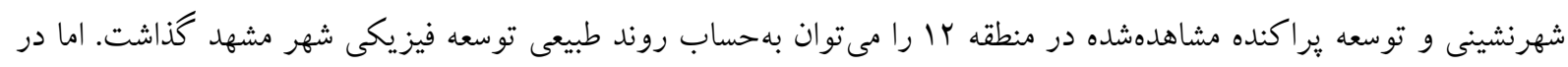

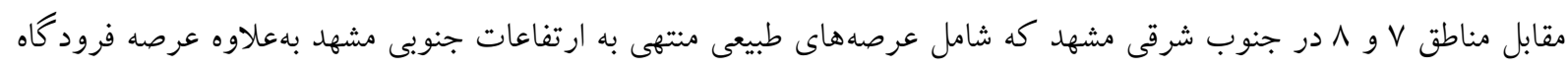

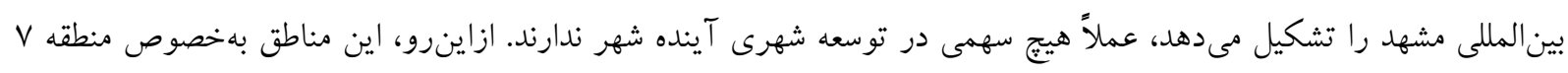

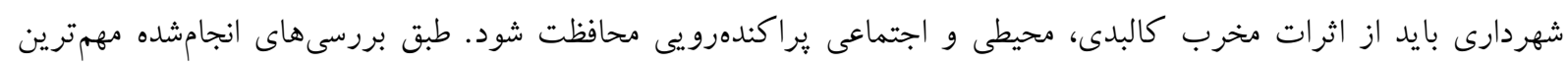

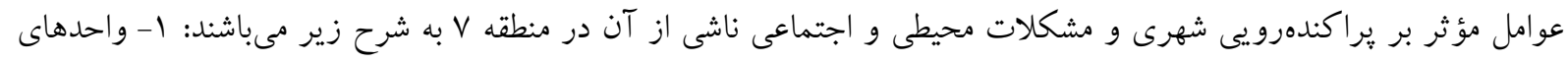

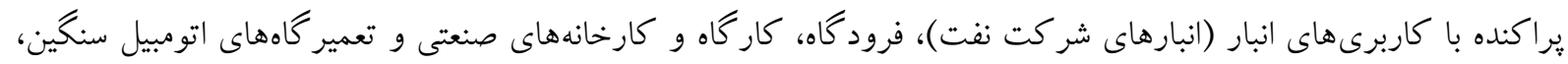

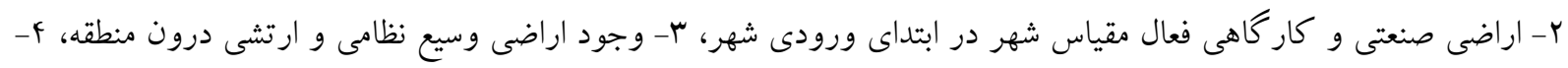

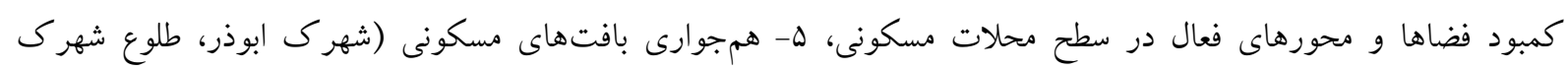

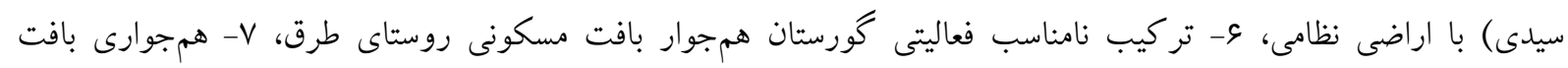

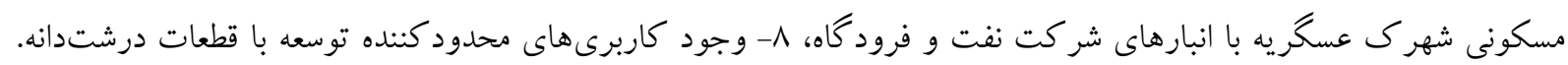

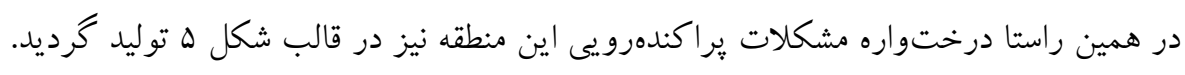

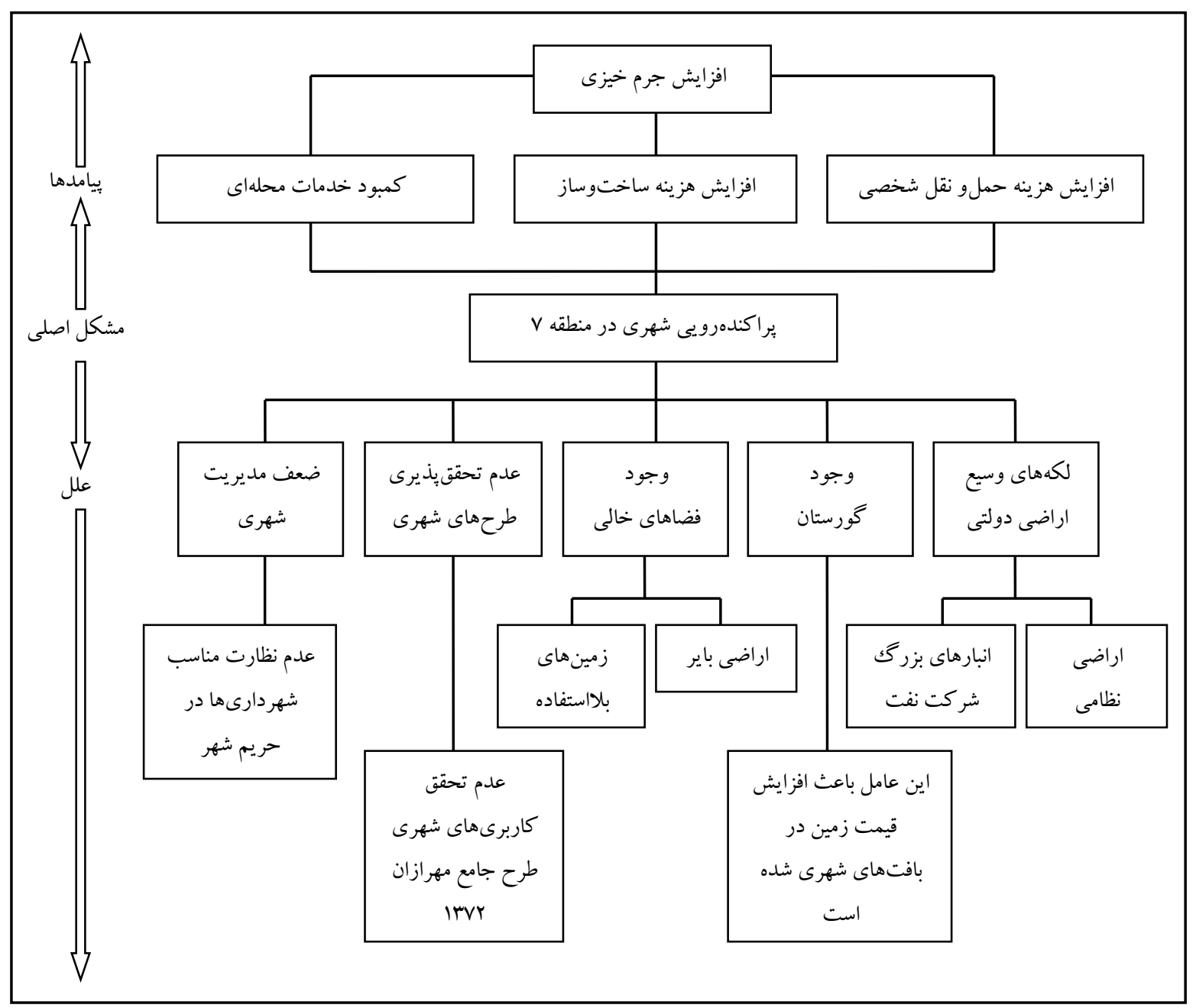

شكل 0- درختواره مشكلات ير اكندهرويى منطقه Y شهردارى مشهد 
در ادامه اين تحقيق بر اساس روش تحليل خوشهاى HCA يك دندرو گرام خوشهاى براى كنترل نتايج شاخص آنترويى در

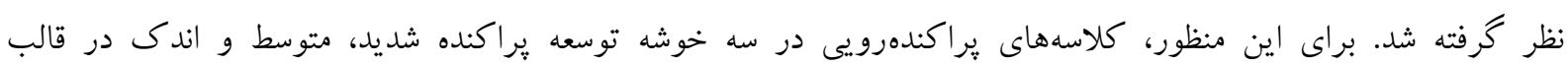
دندرو گرام شكل ع توليد شد.

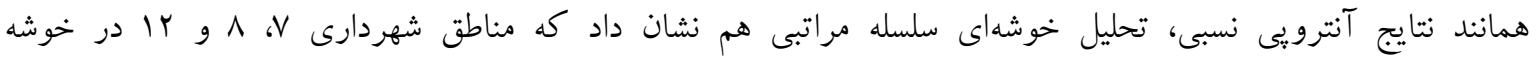

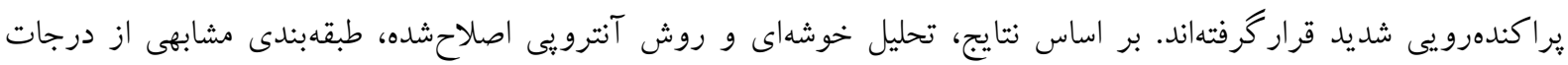

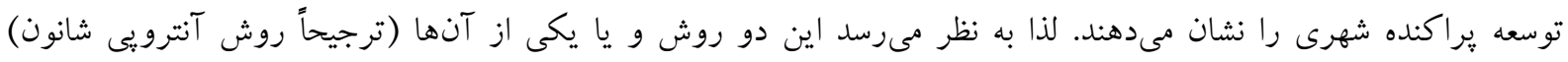

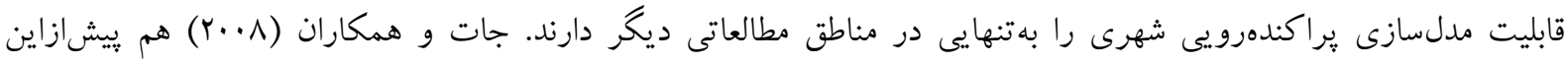

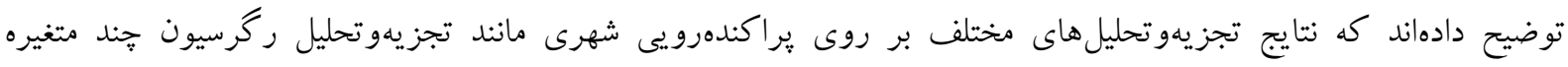

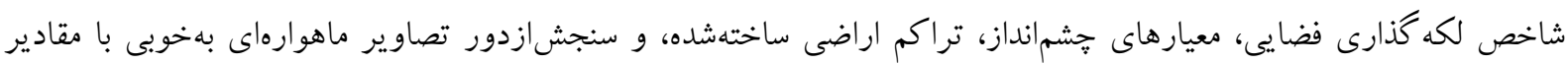

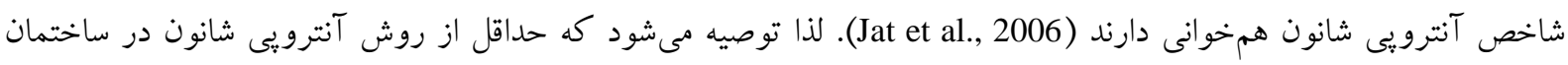
مدلهاى ثبراكندهرويى شهرى استفاده كردد.

كلاسه

\begin{tabular}{|c|c|}
\hline متوسط & $\begin{array}{l}1 \\
1 \\
\varepsilon \\
r \\
0\end{array}$ \\
\hline شديد & $\begin{array}{l}\hat{1} \\
i^{\prime} \\
V\end{array}$ \\
\hline اندك & $\begin{array}{l}9 \\
\text { ثامن } \\
1 \\
11 \\
1 .\end{array}$ \\
\hline
\end{tabular}

شماره منطقهها
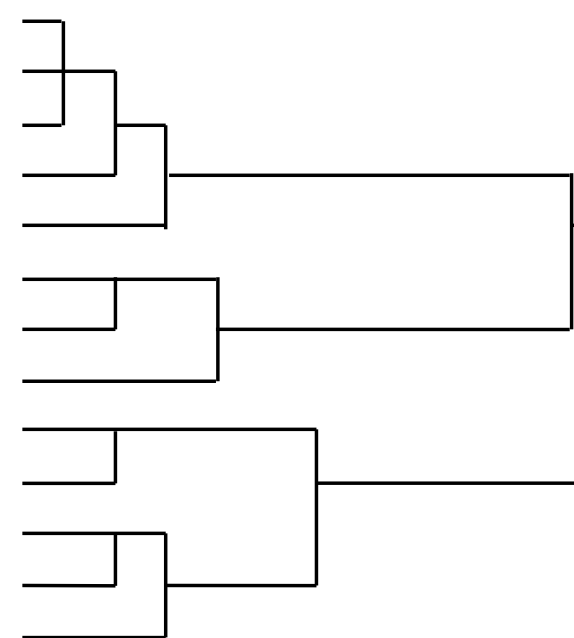

شكل 1 - دندروكرام خوشهبندى مناطق شهردارى مبتنى بر اندازهيرى شاخص يراكندهرويى شهرى

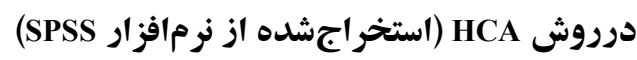

بر آورد همبستخىهاى آمارى

در اين مطالعه، ضريب همبستخى اسبيرمن بين مقادير شاخص ثبراكندهرويى و متغيرهاى مستقل سكونتخاههاى غيررسمى،

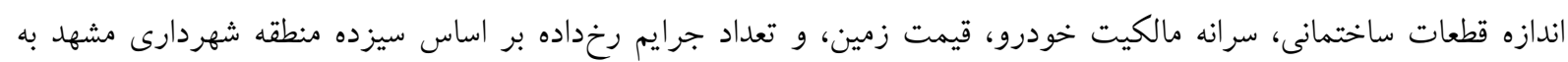

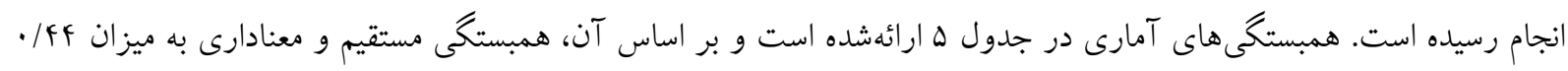

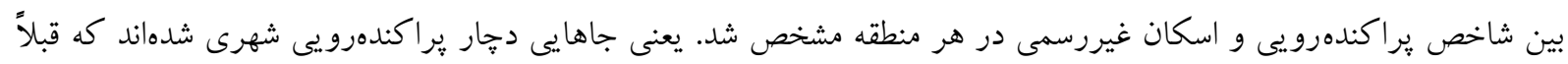

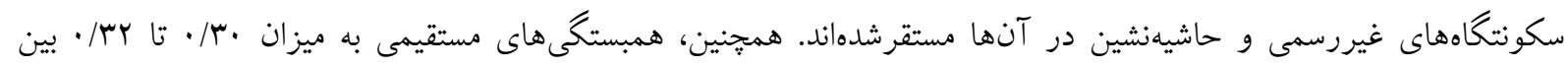

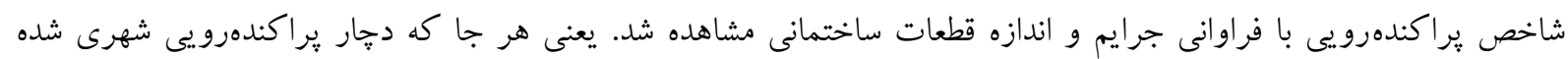

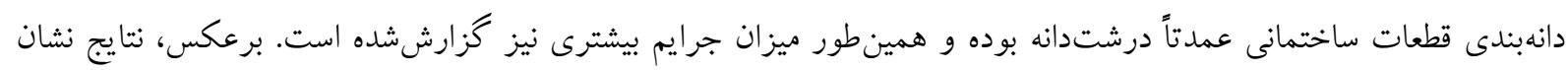

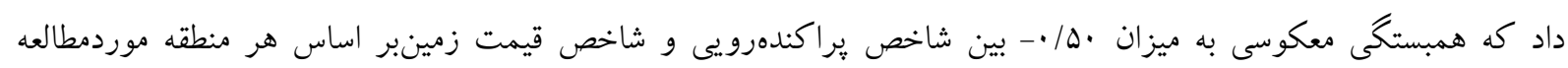




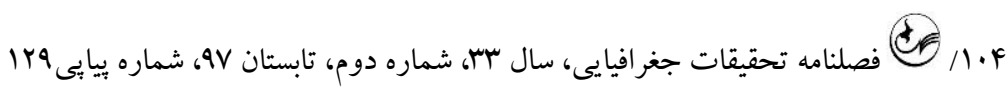
وجود دارد. يعنى هر جا كه دجار يراكندهرويى شهرى شده قيمت زمين شهرى نسبت به ساير مناطق شهر خايينتر بوده است.

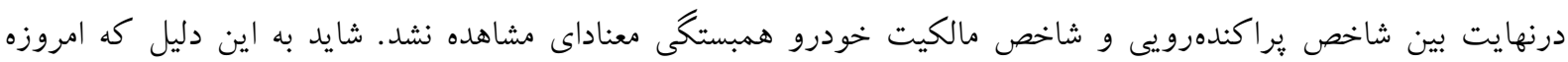

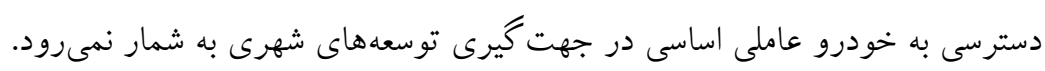

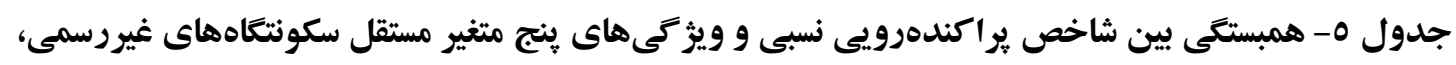
اندازه قطعات ساختمان، سر انه مالكيت خودرو، قيمت زمين و تعداد جر ايم رخد رداده در مشهد

\begin{tabular}{|c|c|c|c|c|c|c|}
\hline تعداد جرايم & قيمت زمين & سرانه مالكيت & اندازه قطعات & سكونتشاههاى & آزمون & متغير \\
\hline.$/ \mu r$ &.$- / 0$ &.$- / . r$ & $\cdot / \mu$. &.$/ F f$ & همبستخى (R) & \multirow{3}{*}{ شاخراكندهرويى } \\
\hline.$/ 1$ & $\cdot / T \Delta$ &.$/ \cdot$ & .1 .9 &.$/ 19$ & $\mathrm{R} 2$ & \\
\hline$\cdot / T \Lambda$ & $\cdot / \cdot \Lambda$ &.$/ 94$ & . & . & معنادارى & \\
\hline
\end{tabular}

يافته هاى تحقيق

يراكندهرويى شهرى به كسترش :براكنده و غير برنامهريزىشده مناطق شهرى اشاره دارد كه به طيف وسيعى از مشكلات

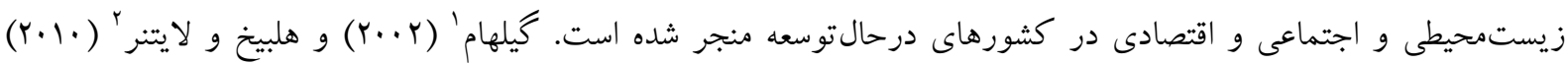

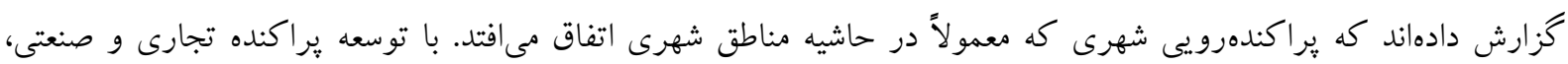

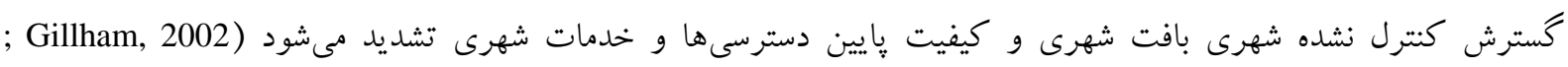

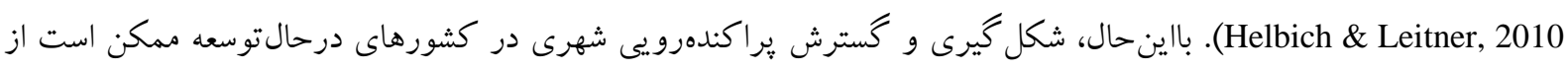

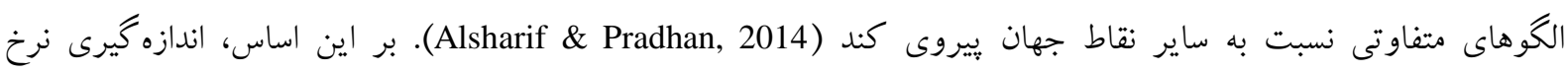

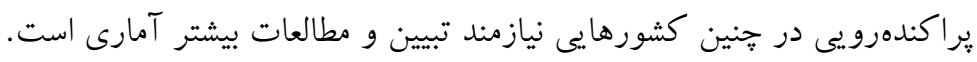

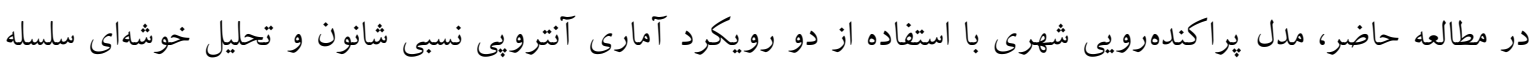

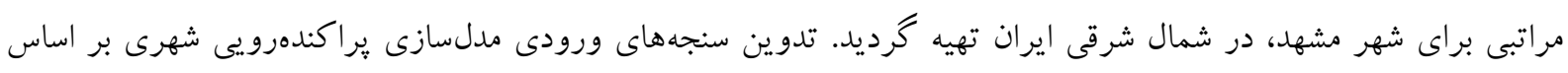

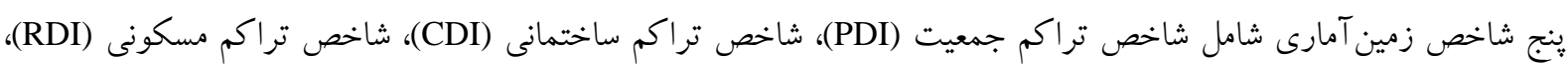

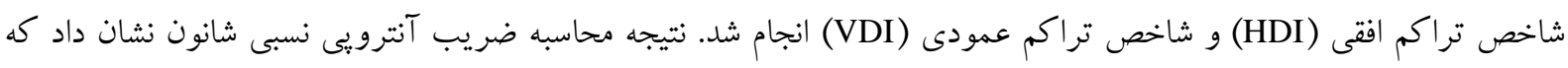

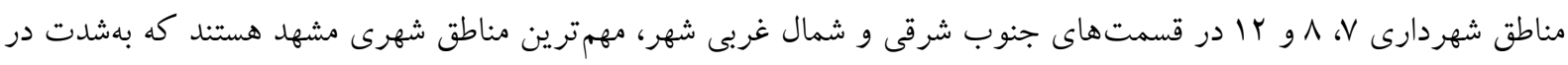

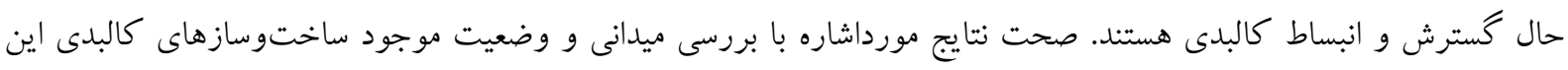

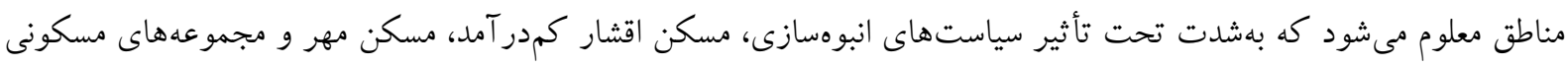

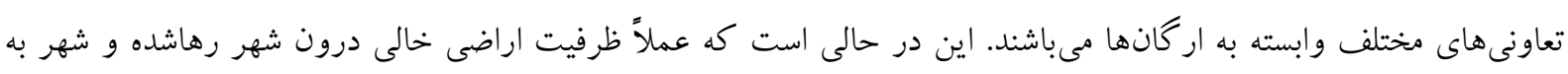

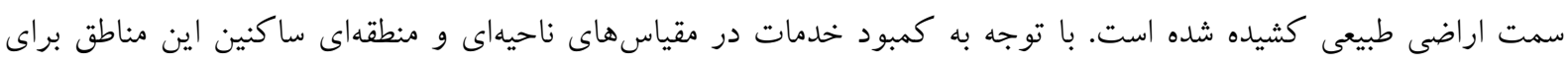

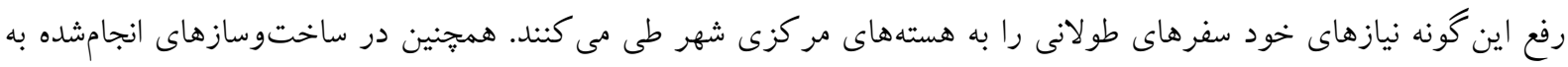

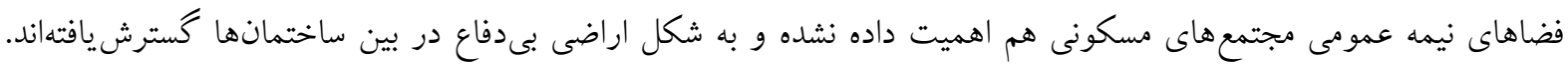

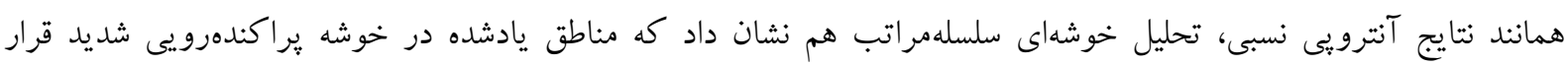

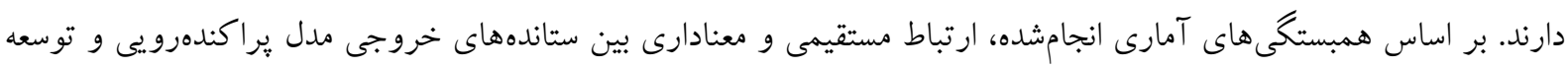


سكونتكاههاى غيررسمى و مجموع فراوانى دادهاى جرمخيزى در هر منطقه به دست آمد. اما برعكس، نتايج نشان داد كه

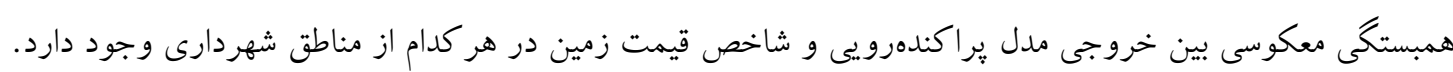

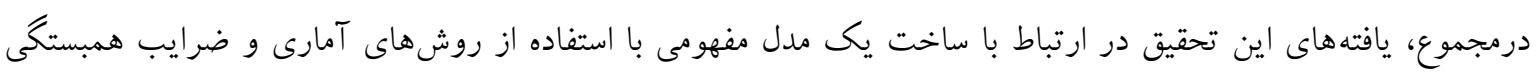

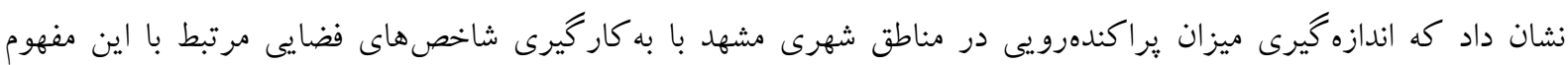

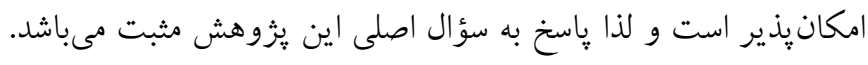

\section{نتيجه گيرى}

كسترش ثراكندهرويى در شهر مشهد بهشدت با رشد سكونتكاههاى غيررسمى و افزايش جرايم ارتباط دارد. در مقابل ارتباط

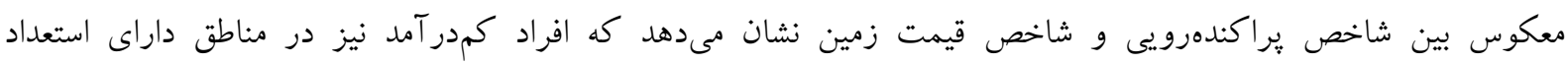

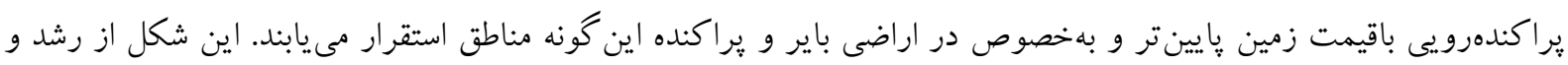

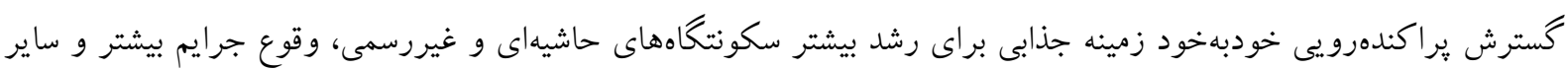

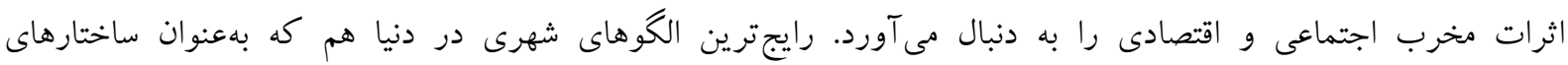

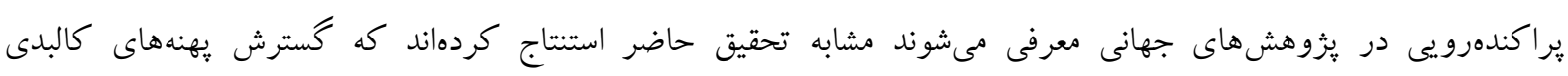

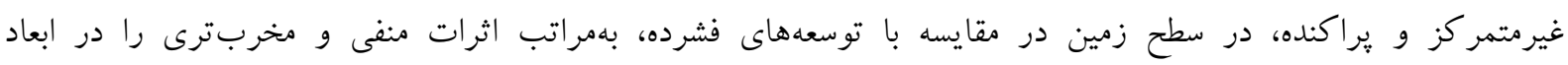

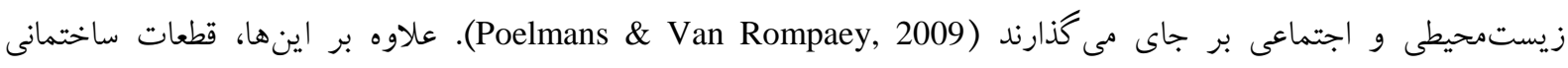

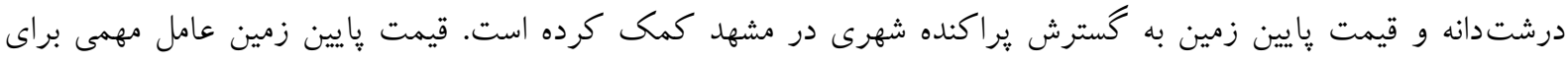

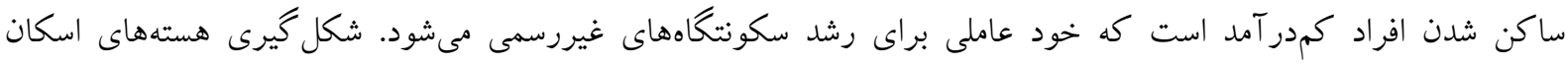

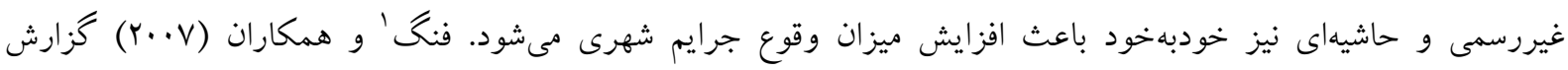

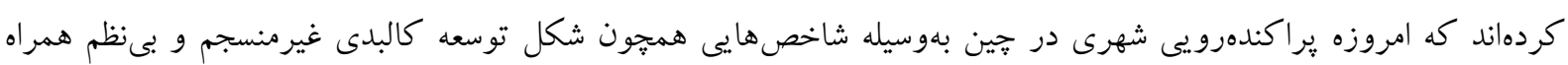

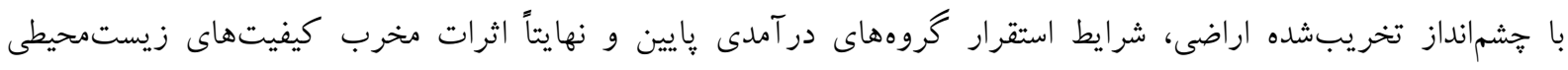

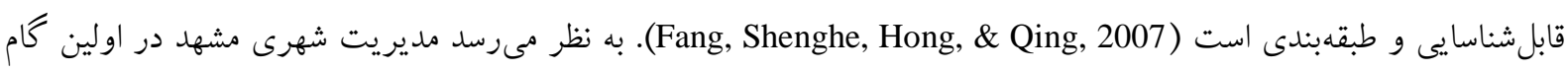

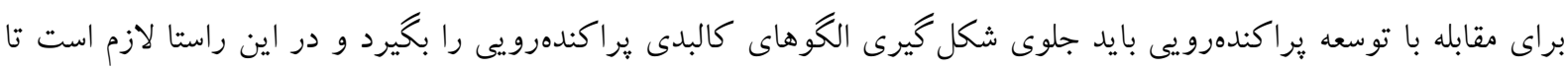
هر جه بيشتر از تغيير كاربرى زمين و تخريب اراضى كشاورزى و طبيعى حاشيه شهر جلو گيرى كند (Rabbani et al., 2018).

\section{ييشنهادها و راهكارها}

امروزه تفكر مورديذيرش در توسعه شهرى، توسعه ساز كاربامحيطزيست است و شهر سازان و برنامهريزان شهرى بايد در

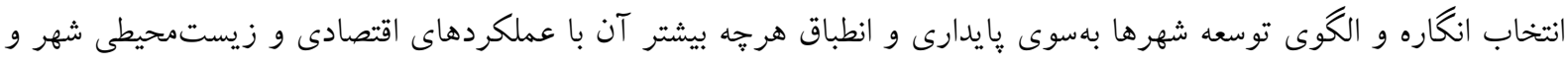

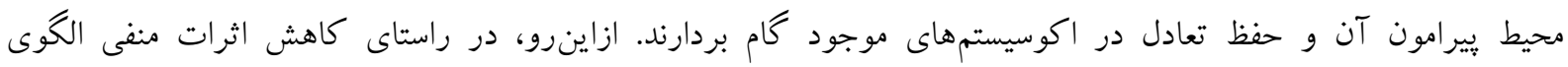

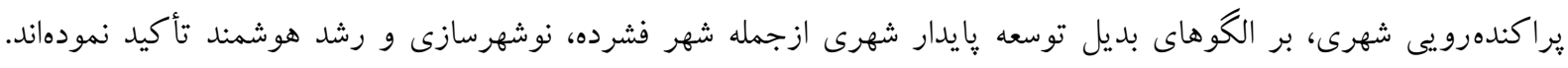

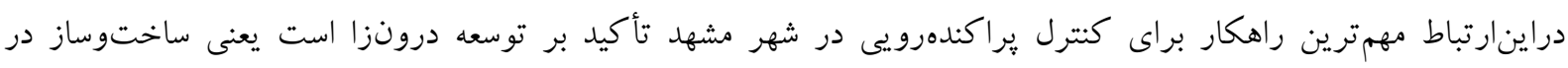

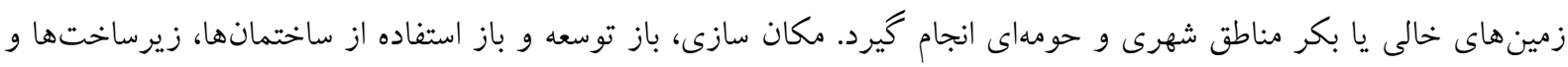

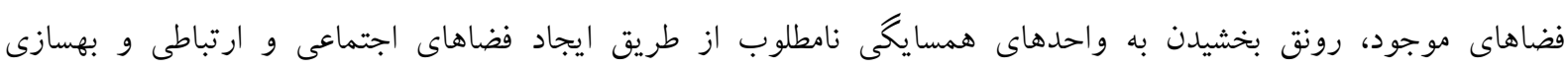

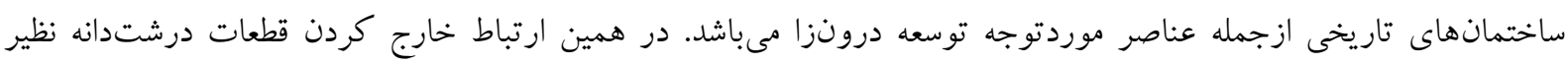




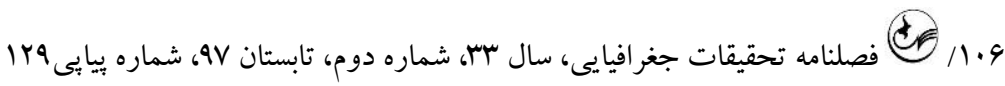

$$
\begin{aligned}
& \text { ياد كانها و مراكز نظامى، انبار نفت و كارخانها زمينه مناسب را براى باز توسعه و باز استفاده از اين اراضى فراهم مى آورد. } \\
& \text { البته ازآنجاكه توسعه فيزيكى شهر امرى اجتنابنايذير است و با ورود جمعيت به شهرها، كسترش فيزيكى شهر نيز ضرورت }
\end{aligned}
$$

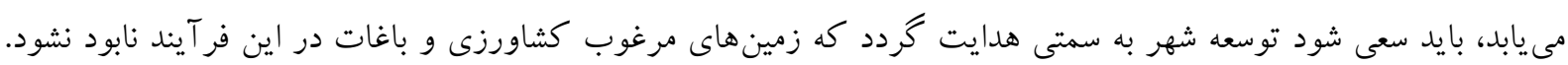

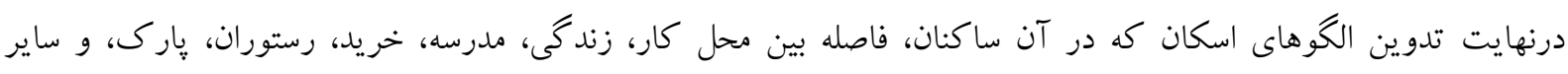

$$
\begin{aligned}
& \text { تسهيلات رفاهى و تجارى را با استفاده از ييادهروى، دوجرخهسوارى و حملونقل عمومى بييمايند ازجمله راهكارهاى مؤثر در } \\
& \text { كاهش اثرات مخرب تيراكندهرويى است. } \\
& \text { سهم نويسندگان: غزاله ربانى ابوالفضلى (نويسنده اول) يزوهشخر اصلى /نگارنده بحث اصلى (•ه.)، سيروس شفقى }
\end{aligned}
$$

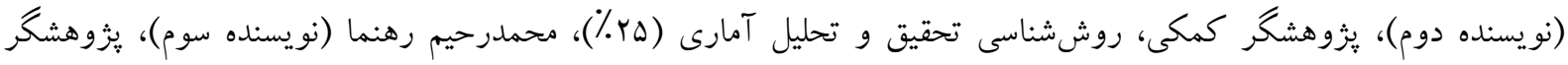

$$
\begin{aligned}
& \text { كمكى، روش شناسى تحقيق و تحليل آمارى (ه广 ٪) } \\
& \text { منابع و مآخذ }
\end{aligned}
$$

Alsharif, A. A. A., \& Pradhan, B. (2014). Urban sprawl analysis of Tripoli metropolitan city (Libya) using remote sensing data and multivariate logistic regression model. Journal of the Indian Society of Remote Sensing, 42(1), 149-163. [DOI:10.1007/s12524-013-0299-7]

Barnes, K. B., Morgan, J. M., Roberge, M. C., \& Lowe, S. (2001). Sprawl development: Its patterns, consequences, and measurement. Towson University, Towson, 1-24 .

Bhatta, B. (2009). Analysis of urban growth pattern using remote sensing and GIS: A case study of Kolkata, India. International Journal of Remote Sensing, 30(18), 4733-4746. [DOI:10.1080/01431160802651967]

Burton, E. (2000). The compact city: Just or just compact? A preliminary analysis. Urban Studies, 37(11), 19692006 .[DOI:10.1080/00420980050162184]

Chatterjee, N. D., Chatterjee, S., \& Khan, A. (2016). Spatial modeling of urban sprawl around Greater Bhubaneswar city, India. Modeling Earth Systems and Environment, 2(1), 14. [DOI:10.1007/s40808015-0065-7]

Effat, H. A., \& El Shobaky, M. A. (2015). Modeling and mapping of urban sprawl pattern in Cairo using multitemporal landsat images, and Shannon's entropy. Advances in Remote Sensing, 4(04), 303-318 . [DOI:10.4236/ars.2015.44025]

Epstein, J., Payne, K., \& Kramer, E. (2002). Techniques for mapping suburban sprawl. Photogrammetric engineering and remote sensing, 68(9), 913-918.

Ewing, R. (1994). Characteristics, causes, and effects of sprawl: A literature review. Environment Urban, 21(2), $1-15$.

Ewing, R. (1997). Is Los Angeles-style sprawl desirable? Journal of the American planning association, 63(1), 107-126 . [DOI:10.1080/01944369708975728]

Fang, J., Shenghe, L., Hong, Y., \& Qing, Z. (2007). Measuring urban sprawl in Beijing with geo-spatial indices. Journal of Geographical Sciences, 17(4), 469-478 . [DOI:10.1007/s11442-007-0469-z]

Farnahad Consultant Engineers. (2009). Building and development comprehensive plan of Mashhad metropolitan: Ministry of Roads and Urban Development. Khorasan Razavi province of Iran. (Persian)

Galster, G., Hanson, R., Ratcliffe, M. R., Wolman, H., Coleman, S., \& Freihage, J. (2001). Wrestling sprawl to the ground: defining and measuring an elusive concept. Housing policy debate, 12(4), 681-717 . [DOI:10.1080/10511482.2001.9521426]

Gillham, O. (2002) .The limitless city: A primer on the urban sprawl debate. Washington, D.C: Island Press.

Helbich, M., \& Leitner, M. (2010). Postsuburban spatial evolution of Vienna's urban fringe: evidence from point process modeling. Urban Geography, 31(8), 1100-1117.[DOI:10.2747/0272-3638.31.8.1100]

Jat, M. K., Garg, P. K., \& Khare, D. (2006). Assessment of urban growth pattern using spatial analysis techniques. Paper presented at the Indo-Australian Conference on Information Technology in Civil Engineering (IAC-ITCE).

Ji, W., Ma, J., Twibell, R .W., \& Underhill, K. (2006). Characterizing urban sprawl using multi-stage remote sensing images and landscape metrics. Computers, Environment and Urban Systems, 30(6), 861-879 . [DOI:10.1016/j.compenvurbsys.2005.09.002] 
Joshi, H., Guhathakurta, S., Konjevod, G., Crittenden, J., \& Li, K. (2006). Simulating the effect of light rail on urban growth in phoenix: An application of the UrbanSim modeling environment. Journal of Urban Technology, 13(2), 91-111. [DOI:10.1080/10630730600872096]

Malik, A., \& Abdalla, R. (2017). Agent-based modelling for urban sprawl in the region of Waterloo, Ontario, Canada. Modeling Earth Systems and Environment, 3(1), 7. [DOI:10.1007/s40808-017-0271-6]

Mansouri Daneshvar, M. R. (2015). Climatic impacts on hydrogeochemical characteristics of mineralized springs: a case study of the Garab travertine zone in the northeast of Iran. Arabian Journal of Geosciences, 8(7), 4895-4906.[DOI:10.1007/s12517-014-1536-2]

Meteorological Center of Khorasan Razavi. (2017). Database of Mashhad Synoptic Station. (1976-2015). from www.razavimet.ir. (Persian)

Mohammady, S., \& Delavar, M. R. (2016). Urban sprawl assessment and modeling using landsat images and GIS. Modeling Earth Systems and Environment, 2(3), 155. [DOI:10.1007/s40808-016-0209-4]

Pham, H. M., Yamaguchi, Y., \& Bui, T. Q. (2011). A case study on the relation between city planning and urban growth using remote sensing and spatial metrics. Landscape and Urban Planning, 100(3), 223-230 . [DOI:10.1016/j.landurbplan.2010.12.009]

Poelmans, L., \& Van Rompaey, A. (2009). Detecting and modelling spatial patterns of urban sprawl in highly fragmented areas: A case study in the Flanders-Brussels region. Landscape and Urban Planning, 93(1), 10-19.[DOI:10.1016/j.landurbplan.2009.05.018]

Polidoro, M., de Lollo, J. A., \& Barros, M. V. F. (2011). Environmental impacts of urban sprawl in Londrina, Paraná, Brazil. Journal of Urban and Environmental Engineering, 5(2), 73-83 . [DOI:10.4090/juee.2011.v5n2.073083]

Rabbani, G., Shafaqi, S., \& Rahnama, M. R. (2018). Urban sprawl modeling using statistical approach in Mashhad, northeastern Iran. Modeling Earth Systems and Environment, 4(1), 141-149 . [DOI:10.1007/s40808-017-0404-y]

Rafiee, R., Mahiny, A. S., Khorasani, N., Darvishsefat, A. A., \& Danekar, A. (2009). Simulating urban growth in Mashad city, Iran through the SLEUTH model (UGM). Cities, 26(1), 19-26. [DOI:10.1016/j.cities.2008.11.005]

Rahnama, M. R., \& Abbaszadeh, G. R. (2008). A comparative study measuring dispersal and compactness in Sydney and Mashhad metropolitans. Geography and Regional Development, 3(6), 101-128. (Persian)

Rahnama, M. R \& ,.Javan, J. (2011). Studies on urban landuse planning of Mashhad metropolitan: Jahad Daneshgahi Publication. (Persian)

Rui, Y. (2013). Urban growth modeling based on land-use changes and road network expansion. (Doctoral Thesis), KTH Royal Institute of Technology, Stockholm, Sweden .

Schneider, A., \& Woodcock, C. E. (2008). Compact, dispersed, fragmented, extensive? A comparison of urban growth in twenty-five global cities using remotely sensed data, pattern metrics and census information. Urban Studies, 45(3), 659-692 .[DOI:10.1177/0042098007087340]

Shahraki, S., Kazemzadeh, A., \& Badami, S. (2014). Spatiotemporal analysis of the physical expansion of Mashhad City and monitoring of land use changes around. Geographical Urban Planning Research, 2(4), 483-499. (Persian)

Singh ,B. (2014). Urban growth using shannon entropy, a case study of Rohtak city. International Journal of Advanced Remote Sensing and GIS, 3(1), 544-552 .

Statistical Centre of Iran. (2011). Macro results of statistical survey. from http://www.amar.org.ir. (Persian)

Tewolde, M. G., \& Cabral, P. (2011). Urban sprawl analysis and modeling in Asmara, Eritrea. Remote Sensing, 3(10), 2148-2165 . [DOI:10.3390/rs3102148]

Thomas, R. W. (1981). Information statistics in geography: Geo Abstr, Norwich.

Yu, X. J., \& Ng, C. N. (2007). Spatial and temporal dynamics of urban sprawl along two urban-rural transects: A case study of Guangzhou, China. Landscape and urban planning, 79(1), 96-109 . [DOI:10.1016/j.landurbplan.2006.03.008]

Yuan, F., Sawaya, K. E., Loeffelholz, B. C., \& Bauer, M. E. (2005). Land cover classification and change analysis of the Twin cities (Minnesota) metropolitan area by multitemporal landsat remote sensing. Remote sensing of Environment, 98(2-3), 317-328[DOI:10.1016/j.rse.2005.08.006] . 